\title{
NERI Research Project
}

Development of Advanced Technologies to Reduce Design, Fabrication and Construction for Future Nuclear Power Plants

Year One Activities Report

DOE Project DE-FCO ${ }_{i}^{3} 99 S F 21898 / A 000$ 


\section{DISCLAIMER}

This report was prepared as an account of work sponsored by an agency of the United States Government. Neither the United States Government nor any agency thereof, nor any of their employees, make any warranty, express or implied, or assumes any legal liability or responsibility for the accuracy, completeness, or usefulness of any information, apparatus, product, or process disclosed, or represents that its use would not infringe privately owned rights. Reference herein to any specific commercial product, process, or service by trade name, trademark, manufacturer, or otherwise does not necessarily constitute or imply its endorsement, recommendation, or favoring by the United States Government or any agency thereof. The views and opinions of authors expressed herein do not necessarily state or reflect those of the United States Government or any agency thereof. 


\section{DISCLAIMER}

Portions of this document may be illegible in electronic image products. Images are produced from the best available original document. 


\title{
Development of Advanced Technologies to Reduce Design, Fabrication and Construction for Future Nuclear Power Plants
}

\author{
Year One Progress Report
}

Project Report, October 2000

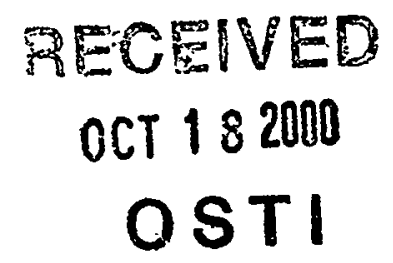

Principal Investigator

J. Michael O'Connell, Duke Engineering \& Services

\author{
Cosponsors \\ Dr. Abhinav Gupta, Assistant Professor, NCSU \\ Dr. Michael Golay, Professor, MIT \\ Dr. Vincent Luk, Sandia National Laboratories \\ Gary Rochau, Sandia National Laboratories \\ Donn Matteson, Westinghouse Electric Company Nuclear Systems
}




\section{DISCLAIMER OF WARRANTIES AND LIMITATION OF LIABILITIES}

THIS DOCUMENT WAS PREPARED BY THE ORGANIZATION(S) NAMED BELOW AS AN ACCOUNT OF WORK SPONSORED OR COSPONSORED BY THE DEPARTMENT OF ENERGY, (DOE). NETTHER DOE, TTS SUB-CONTRACTORS, THE ORGANIZATION(S) BELOW, NOR ANY PERSON ACTING ON BEHALF OF ANY OF THEM:

(A) MAKES ANY WARRANTY OR REPRESENTATION WHATSOEVER, EXPRESS OR IMPUED, (I) WTTH RESPECT TO THE USE OF ANY INFORMATION, APPARATUS, METHOD, PROCESS, OR SIMILAR ITEM DISCLOSED IN THIS DOCUMENT, INCLUDING MERCHANTABILTYY AND FITNESS FOR A PARTICULAR PURPOSE, OR (II) THAT SUCH USE DOES NOT INFRINGE ON OR INTERFERE WITH PRIVATELY OWNED RIGHTS, INCLUDING ANY PARTY'S INTELLECTUAL PROPERTY, OR (III) THAT THIS DOCUMENT IS SUITABLE TO ANY PARTICULARUSER'S CIRCUMSTANCE; OR

(B) ASSUMES RESPONSIBILTY FOR ANY DAMAGES OR OTHER LABILITY WHATSOEVER (INCLUDING ANY CONSEQUENTIAL DAMAGES, EVEN IF THE DOE OR ANY DOE REPRESENTATIVE HAS BEEN ADVISED OF THE POSSIBILTY OF SUCH DAMAGES) RESULTING FROM YOUR SELECTION OR USE OF THIS DOCUMENT OR ANY INFORMATION, APPARATUS, METHOD, PROCESS, OR SIMILAR ITEM DISCLOSED IN THIS DOCUMENT.

ORGANIZATION(S) THAT PREPARED THIS DOCUMENT

Duke Engineering \& Services

Massachusetts Institute of Technology

North Carolina State University

Sandia National Laboratories

Westinghouse Electric Company Nuclear Systems

This is a yearty project report to the Department of Energy for the Nuciear Energy Research Initiative (NERI) program work. This report is intended as an informal report of continuing research, a meeting, or a topical study. It is not a final technical report. 


\section{CITATIONS}

This document was prepared by:

J. Michael O'Connell

Principal Investigator

Duke Engineering \& Services

400 Donald Lynch Blvd.

Marlborough, MA 01752

Dr. Michael Golay

Professor of Nuclear Engineering

Massachusetts Institute of Technology

77 Massachusetts Avenue

Cambridge, MA 02139

Dr. Vincent Luk

International Nuclear Safety Dept.

Sandia National Laboratories

Albuquerque, NM 87185-0744

Mr. Donn Matteson

Westinghouse Electric Company Nuclear Systems

2000 Day Hill Road

Windsor, CT 06095
Dr. Abhinav Gupta

Assistant Professor

North Carolina State University

413 Mann Hall

Raleigh, NC 27695-7908

Gary E. Rochau

Advanced Nuclear Concepts

Sandia National Laboratories

Albuquerque, NM 87185-1178

This document describes research sponsored by the Department of Energy and was performed, in part at Sandia National Laboratories. Sandia is a multiprogram laboratory operated by Sandia Corporation, A Lockheed Martin Company, for the U.S. Department of Energy under Contract DE-AC04-94AL85000.

The support of Mr. Amadeus Burger of Construction Systems Associates of Marietta, GA is gratefully acknowledged. 


\section{CONTENTS}

1 EXECUTIVE SUMMARY ................................................................ 1-1

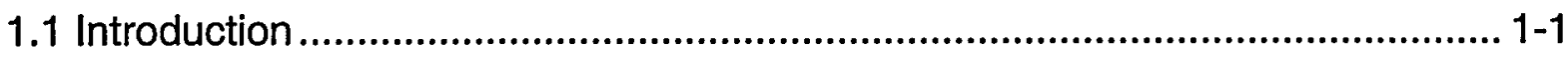

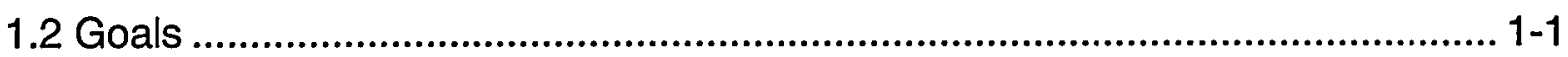

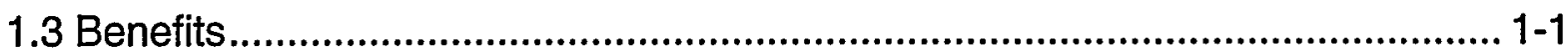

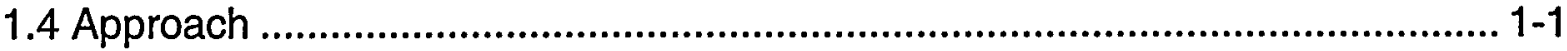

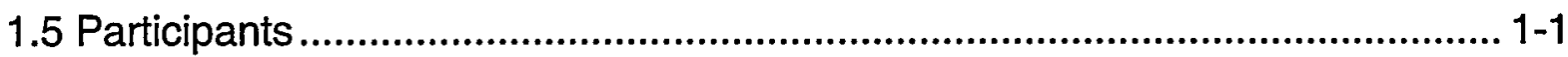

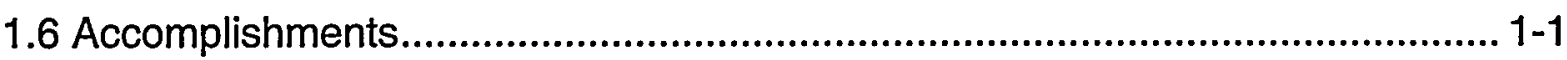

1.7 Milestones/Deliverables/Schedule Issues.................................................... 1-2

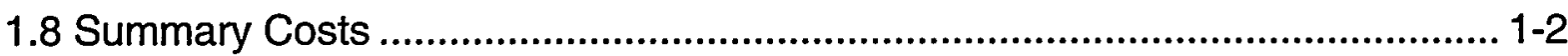

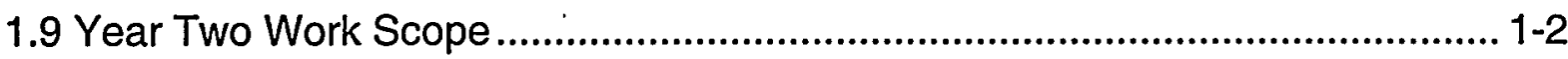

2 INTRODUCTION................................................................................... 2-1

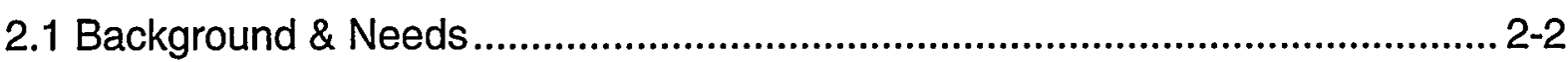

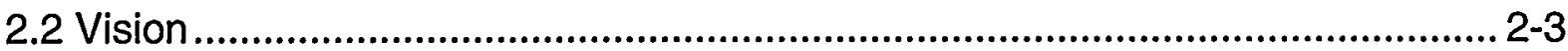

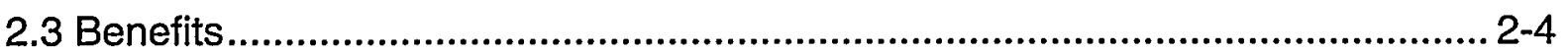

3 PROJECT GOALS, ORGANIZATION, APPROACH......................... 3-1

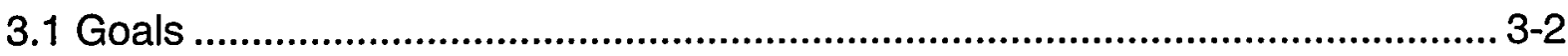

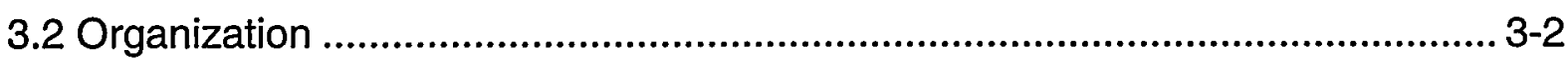

3.3 Approach ....................................................................................................... 3-2

4 TASK DESCRIPTIONS AND RESULTS ......................................... 4-1

4.1 Task Y-1.1 Build a Productivity Model ............................................................... 4-2

4.1.1 Task Y-1.1 Approach.......................................................................... 4-2

4.1.2 Construction and Startup Schedule .................................................... 4-2

4.1.3 System 80+ Construction Techniques............................................... 4-5

4.1.4 Construction and Startup Schedule ........................................................ 4-7

4.1.5 Productivity Model Construction ........................................................... 4-8

4.2 Task Y-1.2 Develop DPCIT Metrics ........................................................ 4-11

4.2.1 Task Y-1.2 Approach...................................................................... 4-11

4.2.2 General Measurement Development Methodology ................................. 4-11

4.2.3 Measures of Quality............................................................................ 4-12

4.2.4 Measures of Production...................................................................... 4-13

4.2.5 Measures of DPCIT Project Impact .................................................. 4-14

4.2.6 Proposed Measurement Categories ......................................................... 4-15

4.3 Task Y-1.3 Develop 3D/4D Model of Base Plant ......................................... 4-19

4.3.1 Task Y-1.3 Approach.................................................................... 4-19 
4.3.2 3D/4D Expected Benefits ................................................................. 4-19

4.3.3 Construction Modeling Results.............................................................. 4-21

4.4 Task Y-1.4 Research Other Industry Practices........................................... 4-27

4.4.1 Task Y-1.4 Approach........................................................................... 4-27

4.4.2 Observation of Related Industry Practices .......................................... 4-27

4.5 Task Y-1.5 Examine Modularity ................................................................ 4-30

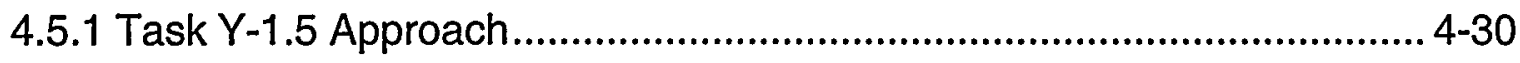

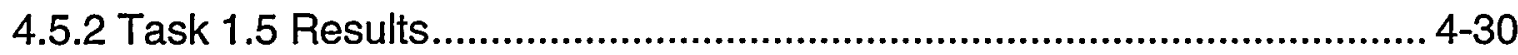

4.6 Task Y-1.6 Examine Upcoming Technologies ............................................ 4-33

4.6.1 Task Y-1.6 Approach......................................................................... 4-33

4.6.2 Impacts of Upcoming Technologies ................................................. 4-33

4.7 Task Y-1.7 Evaluate Excess Margin ..................................................... 4-37

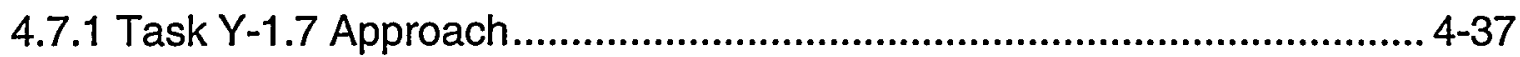

4.7.2 Seismic Behavior of Electrical Cabinets and Control Panels.................. 4-37

4.7.3 Building-Piping Systems.......................................................................... 4-38

4.7.4 Electrical Cabinets and Control Panels ................................................ 4-39

4.8 Task Y-1.8 Component and Quality Lead Time Constraints......................... 4-41

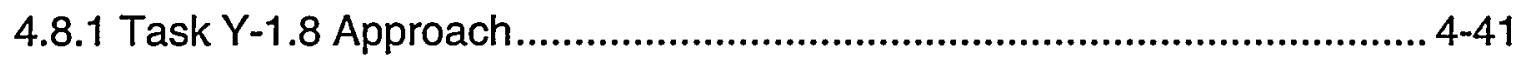

4.8.2 Nuclear Quality Requirement Issues .................................................. 4-41

4.8.3 Steam Generator Fabrication ....................................................... 4-43

4.8.4 Steam Generator Fabrication ........................................................ 4-44

4.8.5 Steam Generator Fabrication Shortening Strategies .............................., 4-45

4.9 Task Y-1.9 Develop System Dynamics Model for DPCIT ............................... 4-48

4.9.1 Task Y-1.9 Approach............................................................................4-48

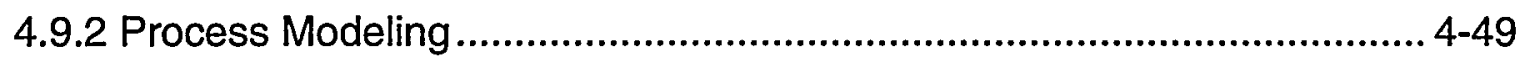

4.10 Task Y-1.10 Linking Finite Element Codes and Design Software................ 4-51

4.10.1 Task Y-1.10 Approach..................................................................... 4-51

4.10.2 Target Component for Design to Analysis .......................................... 4-52

4.11 Task Y-1.11 Examine Containment Margins and Uncertainties................... 4-53

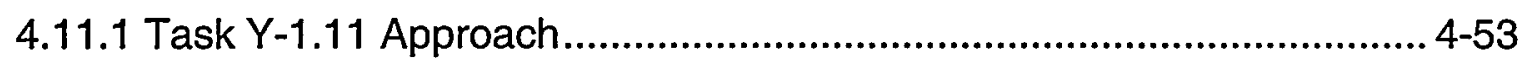

4.11.2 Containment Margin Examination Results........................................... 4-53

5 MODEL DEVELOPMENT .................................................................. 5-1

5.1 Product Model................................................................................................... 5-2

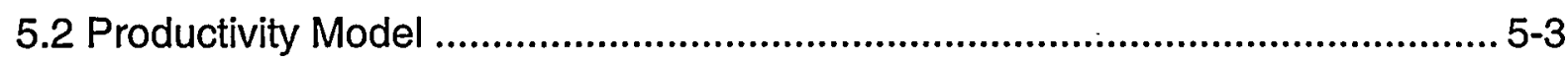

5.3 Process Model and the Management of Complex Projects ............................ 5-3

5.3.1 Process Model Element - Dependency Structure Matrix ........................... 5-3

5.3.2 Process Model Element - Bayesian Belief Networks ................................ 5-5 
6 EXPECTED RESULTS NEXT YEAR................................................... 6-1

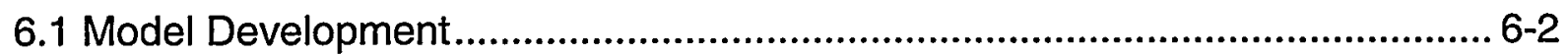

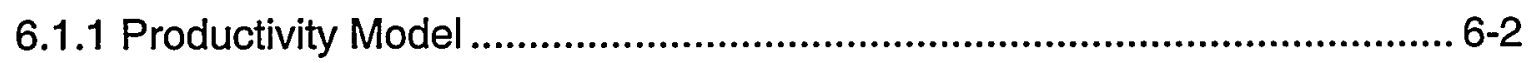

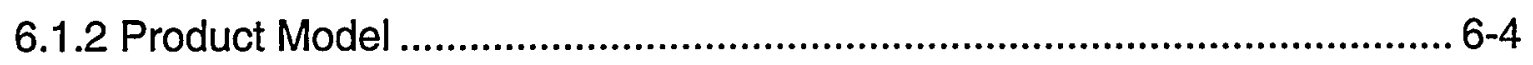

6.1.3 Process Model........................................................................................... 6-5

6.2 Containment and Structural Construction Simplifications ................................ 6-5

6.3 Project Risk Management Technologies ..................................................... 6-6

6.4 Information Technologies ........................................................................... 6-6

APPENDIX A: PROJECT PARTICIPANTS

APPENDIX B: LIST OF PUBLICATIONS AND REPORTS

APPENDIX C: KEY PRESENTATIONS \& MEETINGS

APPENDIX D: BIBILOGRAPHY 


\section{EXECUTIVE SU MMARY}

\subsection{Introduction}

This report provides a summary of the Year One research activities of the Department of Energy's Nuclear Energy Research Initiative (NERD) project focused on development of technologies to reduce the capital costs and construction schedule time line for future nuclear power plants.

\subsection{Goals}

Identify those mechanisms that can be applied to reduce the overall cycle time for the Design, Procure, Construction, Installation and Testing (DPCIT) for an advanced nuclear plant by $40 \%$. Provide increased confidence in the overall process of ensuring an advanced nuclear project can be built within the cost and schedule targets assumed for a competitive energy marketplace.

\subsection{Benefits}

New nuclear power plants possess schedule and related capital cost risk premiums that preclude their increased use as solutions for carbon emissions reduction and improved electric system reliability.

\subsection{Approach}

The project team expects to incorporate insights from a variety of commercial technology improvement programs coupled with a detailed analysis of nuclear plant engineering alternatives. A series of models to capture the insights are serving as the vehicle for presenting the findings.

\subsection{Participants}

Duke Engineering \& Services (DE\&S) with support from Westinghouse Electric Company Nuclear Systems (WENS), the Massachusetts Institute of Technology (MIT), North Carolina State University (NCSU) and Sandia National Laboratories (SNL) is accomplishing the research.

\subsection{Accomplishments}

The project team has accomplished an initial identification of capital cost and schedule reduction strategies. One key insight into the reduction of capital cost and schedule is that backfitting new technologies into pre-existing designs does not offer as significant a payoff as working with new designs as they are being created. This favors the Generation 
IV Advanced Nuclear Plants in that these plants are either in the process of incorporating the kinds of improvements this project has examined, or there is the potential to incorporate these insights before finalizing the design.

\subsection{Milestones/Deliverables/Schedule Issues}

Year One work was performed in 1999 and 2000 with Year Two work scheduled during 2000 and 2001 with the Year Three work wrapping up in 2002.

\subsection{Summary Costs}

$\$ 731,435$ has been spent as a result of Year One work.

\subsection{Year Two Work Scope}

The Year Two research efforts will incorporate the insights gained from Year One and focus on the following areas:

- New Design Technologies to Achieve Capital Cost and Cycle Time Reductions

- Power Uprates Made Possible Through New Design Methods

- Incorporation of Risk Informed Impact

- Information Technologies that Facilitate Collaborative Engineering

- Plant Fabrication and Construction Technology Advances

- Evaluation of Evolving Passive Design Impacts

- Reduction in Project Execution Risk with New Management Assessment Tools

The overall goal for Year Two is to continue with cost reduction application while at the same time working to identify those strategies that will also reduce the risk and ensure that the proposed shortened schedule can be accomplished. 


\section{INTRODUCTIO N}

Revision 0

10-12-00 


\subsection{Background \& Needs}

The purchase of an advanced nuclear power plant is initially based upon the assessment of the total capital cost on a dollar per installed kilowatt electric coupled with the planned operations and maintenance costs on a operating cost per installed kilowatt electric. Both these metrics are the yardsticks by which nuclear power plants are compared against market alternatives of gas fired generation or coal fired generation. While the existing fleet of nuclear power plants in the United States operates cost effectively and competitively in a partially deregulated market, the decision to invest in new nuclear generation is contingent upon not only the capital cost per $\mathrm{kW}$ installed, but also the confidence with which the schedule of delivery can be completed. The prior work sponsored jointly by the Department of Energy and the Electric Power Research Institute in the Advanced Light Water Reactor (ALWR) program produced reactor plant designs that were optimized for operations and maintenance expenditure, but not capital cost or schedule as the research initiatives were conducted when the electric power system had not experienced the impact of deregulation.

Deregulation has since altered the analysis of new power plant ordering to balance both capital costs and operations and maintenance costs since in the new energy market, there is no programmatic support for investment decisions other than the economics of the power generation source and its fuel. Figure 1 below illustrates the decision logic to be satisfied for new nuclear plant orders.

\section{Requirements for New Plant Construction Decisions}

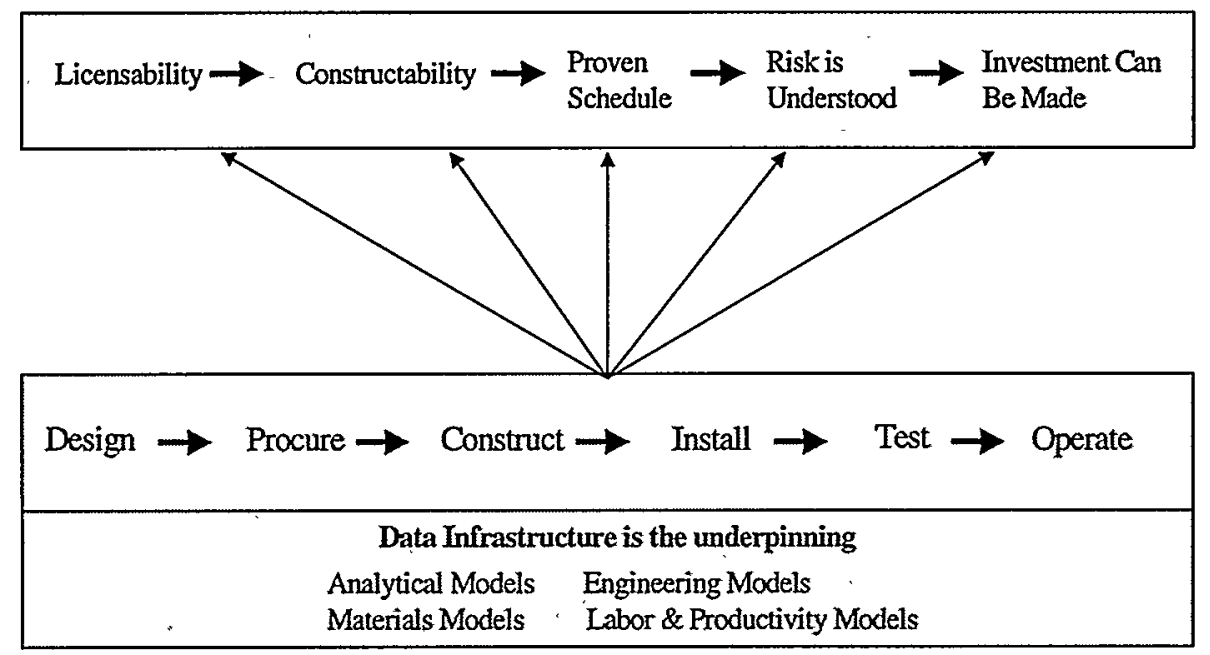


Therefore the nuclear industry faces two major hurdles to overcome, a lower competitively priced nuclear nit coupled with a schedule that is competitive and most importantly, believable to the prospective investor.

The ALWR designs represent potential starting points for examining capital cost reductions, however these designs are burdened by the considerations of a regulated environment in which the design bases considerations date to the dawn of the nuclear power era when the technology was new and therefore design margin were created to offset the lack of experience. So there is much to examine for the basic design of a next generation nuclear plant. However, design of a competitive plant is merely a prerequisite to the next stage that is the construction of a plant. Promising reactor designs would have to be built using the same strategies that were found to be less than adequate for controlling costs in the 1970's.

Thus, delivery of a reactor plant within the three constraints of quality, cost and schedule is not currently achievable in a deregulated market. The challenge is therefore to redefine the rules of the game to make success possible. Work must be done to link prior industry research that has examined specific incremental improvement strategies with applications of information technology and new thinking on coordination of businesses to produce dramatic reductions in the capital cost of new reactor plants. This project's focal point for keeping score of potential improvements is on the total cost and cycle time associated with the Design, Procure, Construct, Install, and Test (DPCIT) cycle. By examining each of these activities in building a plant, we expect to apply new thinking and improvement techniques that have been developed in other industries.

\subsection{Vision}

The DPCIT project represents a merger of information technologies and supply chain management principles with design and construction improvements. The project will focus on process and along the way adopt the appropriate tools to execute the process. Figure 2 below provides a visual image of the intent of the DPCIT project.

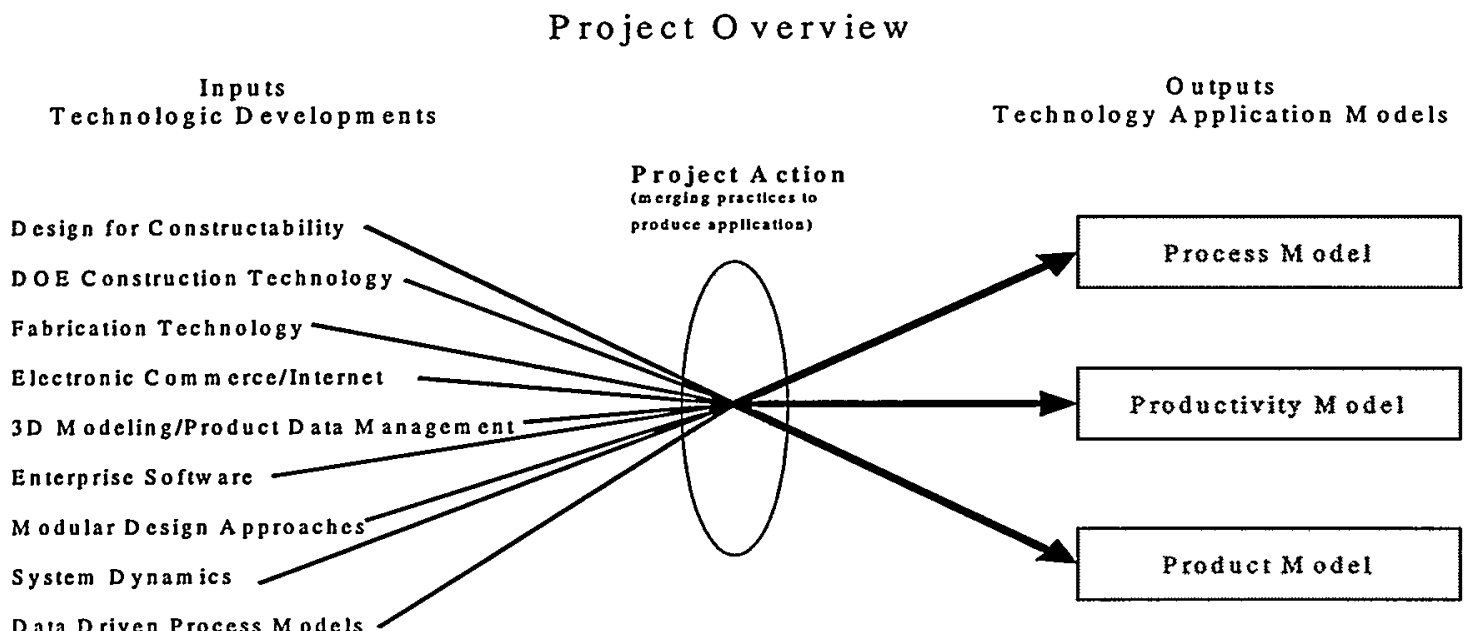




\subsection{Benefits}

The benefits of our approach and broad review of non-nuclear technology advances coupled with improvements within the nuclear industry and related NERI projects are:

1. to identify the recipe for successful development of the next generation reactor plants in terms of their cost structure,

2. provide the ability to be constructed swiftly and confidently, and

3. identify the fundamental changes in practices needed to accommodate the competitive energy marketplace for new reactor designs.

The project expects to address key improvement technologies that can be applied to both reduce a nuclear plant's costs and address the issue of schedule and capital at risk. 
3 PROJECT GOA LS, ORGANIZATION, APPROACH 


\subsection{Goals}

The goal of the DPCIT project team is to identify those methods that can deliver a $40 \%$ reduction in capital cost and schedule for a future nuclear power plant. Given the starting point of the ALWR program's benchmark of $\$ 1500$ per $\mathrm{kW}$ installed and a 60 month construction schedule, the targeted reductions translate into a power plant built for $\$ 900$ per $\mathrm{kW}$ and 36 months from first concrete to fuel load. Ideally these techniques and innovations would be able to be demonstrated on the planned Generation IV reactor plants which are under conceptual and detailed development. Many of innovations planned in this project should be applicable to most reactor technologies since the concepts under consideration are not linked to a specific reactor design, though the proposed reductions will be demonstrated using pressurized water reactor technology.

\subsection{Organization}

Duke Engineering \& Services leads the team with an assigned Project Manager who has the accountability for all budgetary and contractual matters between DE\&S and DOE as well as the sub-contract organizations. Since Sandia National Laboratory (SNL) funding is provided separately, there is no management of the SNL funds.

Project team members are provided from the following organizations:

- Massachusetts Institute of Technology, Nuclear Engineering Department

- North Carolina State University, Civil Engineering Department

- Sandia National Laboratories, Advanced Nuclear Concepts and International Nuclear Safety Department

- Westinghouse Electric Company Nuclear Systems

Task leaders from each of the participating organizations are represented at project meetings and on conference calls.

\subsection{Approach}

Given the diverse nature of the team members and their own interests and individual strengths, the project has been organized with tasks assigned to specific team members. Generally, each team member has been assigned a task or set of tasks with the outcomes being brought together via the annual and final technical reports as well as incorporating insights into the Process, Product, and Productivity models. 


\section{TASK DESCRIP TIONS AND RESULTS}




\subsection{Task Y-1.1 Build a Productivity Model}

\subsubsection{Task Y-1.1 Approach}

In order to evaluate the Design, Procure, Construct, Install, Test (DPCIT) cycle for nuclear power plant construction, it is necessary to understand the processes and activities, and their relationships to each other. The processes, activities and their relationships to each other represent the Process Model of the DPCIT cycle. The Process Model is commonly depicted as a logic network schedule. To accomplish this objective, a construction and startup schedule was developed for the System $80+$ plant.

The logic network provides the tool to determine the impact of the relationships between the required activities to determine the critical activities to the completion of the project. With the knowledge of these critical activities, assessments are performed to determine alternatives that can reduce the overall schedule. These alternatives can include changes to the activity relationships and durations (Process Model), changes to the design to mitigate barriers to the completion of construction (Product Model), and improvements in the methods used to perform the required activities (Productivity Model). As the changes are implemented in the logic network, the effect of the changes can be evaluated relative to the initial (baseline) schedule. The evaluation provides the means to measure the impact of the improvements.

The emergence of three-dimensional models of the plant structures and equipment in recent years presented the possibility of further increasing the understanding of the threedimensional model (Product Model) in terms of the construction and startup schedule (Process Model). It was anticipated that the insight gained from developing a visual representation of the Product Model combined with the Process Model would assist in the evaluation of the DPCIT cycle and lead to improvements in both the construction process and the plant design. As a result, a four-dimensional software Application was developed and implemented for use in the evaluation of the Process Model.

\subsubsection{Construction and Startup Schedule}

A logic network schedule was developed using Primavera Suretrak Project Manager ${ }^{\circledR}$ software. The schedule is based on the 49 month schedule planned for the Lungmen System $80+^{\mathrm{TM}}$ Advanced Light Water Reactor. The 49-month schedule represents the period from the start of pouring of the first structural concrete to completion of loading the fuel in reactor vessel. The current System $80+$ construction and startup schedule is 47 months.

The overall construction and startup schedule was developed at Level 2 detail in Gantt Chart format to establish the overall plan for the Construct, Install and Test portion of the DPCIT cycle. The Level 2 detail is not sufficient to present a meaningful evaluation of the schedule and plant model. Therefore, detailed Level 3 schedule was developed for the Nuclear Island 
as part of the effort. The schedule includes approximately 3,600 activities for construction and startup activities. This includes Level 1 Milestone and Level 2 Summary activities.

The construction and startup schedule was developed in two segments, a segment addressing construction and equipment installation activities (including performance of construction testing) and a segment to conduct startup and test activities. Construction and equipment installation activities are related to specific components (objects) and areas of the plant. The startup and test activities are related to plant systems and subsystems. As the DPCIT cycle proceeds, the focus changes from a component and area based view to a view that is based on the overall plant systems.

These two succinctly different aspects of the overall schedule were independently created and debugged before being merged into a common schedule. Once merged, refinements were made to the integrated schedule to optimize activities between regions and elevations, and among plant systems.

The construction schedule includes the structures and equipment within the Nuclear Island. The reactor building, the containment sub-sphere, and the annex building were sub-divided into regions within each major elevation. For each region, a logic network was developed to:

- Prepare for concrete pours,

- Pour and cure concrete,

- Complete architectural finishes,

- Install mechanical equipment,

- Install large-bore piping,

- Install cable trays,

- Install small-bore piping,

- Install conduit,

- Install electrical equipment,

- Pull and terminate cables,

- Install HVAC ducts,

- Install room air handlers,

- Install instrumentation.

Large equipment in a region was scheduled for installation as soon as possible after curing of the concrete for that region was complete, and before work on the next elevation, or other activities in the region were begun. This approach allowed installation of bulky items to occur with a minimum of interfering structures in place and/or other possibly impeding construction activities going on in the area. Installation of the remaining equipment was scheduled in essentially the sequence as listed above. The logic networks for the individual regions were linked to generate a schedule for completion of construction and equipment installation at each elevation. Within each elevation, systems that include components and/or equipment that could be prerequisite tested as construction was on-going at higher elevations were terminated at a milestone activity following the completion of construction testing. This milestone formed the link to the startup and test schedule. 
The construction schedule was developed on the basis that as the concrete and structural work in an area was completed, the equipment installation would be started in the completed area. The concrete and structural work would continue to the higher elevations of the plant.

A number of key decisions affecting the construction sequence were incorporated in the schedule such as:

- Large equipment is installed Over-the-Top and placed in approximate position before the room is closed from above by on-going structural work.

- Pre-fabrication of the Steel Containment Vessel (SCV) in rings adjacent to the containment building and setting of the rings using a large capacity mobile crane.

- Pre-fabricated liners for pools and lined concrete tanks used as the concrete forms.

- Multiplexed instrumentation signals to decrease the amount of cable and terminations.

Equipment activities are sequenced to provide the maximum workspace for installation of large, heavy items first, followed by lighter and more fragile items later in the sequence. Generally, mechanical equipment (tanks, heat exchangers, and pumps) is aligned and grouted as soon as the area is closed and painted. Large bore pipe and supports are installed next in the sequence, followed by cable tray, HVAC equipment including ducts, and small bore pipe. Electrical equipment is installed at least two floors below on-going civil construction to provide protection from the weather. After electrical equipment is installed, electrical conduits are located and cable is installed.

The construction schedule assumes that equipment will be available to support the early start date for installation. It is anticipated that engineering and procurement activities will be incorporated in the future to identify any potential impact of long lead items on equipment installation. Construction tests of installed equipment and systems are performed as the equipment is energized by level from the bottom of the plant up, depending on the isolation points within the fluid systems. Startup testing is performed on a system basis as the equipment is turned over from construction to the startup organization.

The startup and test schedule was developed based on an experience-based KSNP plant startup and test schedule and modified to allow testing to commence immediately upon completion of the necessary construction activities at a given elevation. The KSNP plant design is based on the System 80 design that, in turn is closely related to the System 80+ design. Startup/test activities for each system generally consist of:

- System flush and hydrostatic testing

- Static prerequisite testing (component and sub-system level),

- Dynamic prerequisite testing,

- System pre-operational testing. 
Activities for static and dynamic prerequisite testing were generated, as appropriate for each system, to allow component, equipment and/or sub-system level prerequisite testing to commence immediately upon completion of construction and equipment installation/construction testing at the individual plant elevations. These activities were linked to their appropriate construction testing completion milestones.

Startup testing of the Nuclear Island requires the availability and corresponding startup of systems in the Turbine Island and Balance of Plant. Equipment not in the Nuclear Island but that is required for startup, such as the switchyard and transformers, auxiliary steam, compressed gas supply equipment, and demineralized water production equipment, is included in the schedule to define the required need dates.

Prerequisite testing was scheduled for each system from the lower to the higher elevations as construction at the individual elevations was completed. The prerequisite tests were subsequently tied into an integrated system pre-operational test activity, which represents the last activity prior to system turnover to Plant Operations in preparation for integrated plant hot functional testing and/or fuel loading. Startup and testing activities following the fuel loading activity are shown in the schedule in the form of summary activities for major evolutions. Other notable assumptions are that construction activities are performed on a 20 hour per day, seven day per week schedule and system startup activities are performed on a 24-hour per day, seven day per week schedule.

\subsubsection{System $80+$ Construction Techniques}

The System 80+ plant considers limited application of modularization and advanced construction techniques to ensure that the construction schedule will be met. A System $80+$ constructability program was developed based on the Electric Power Research Institute's (EPRD) Utility Requirements Document (URD) schedule requirement of 48 months from First Concrete to Fuel Load. Implementation of the program is effected by a number of issues that limited the application of modularization. The schedule was developed based on the employment of traditional construction techniques necessary to meet the URD schedule, rather than by modularization and advanced construction considerations. The detailed engineering was not been completed during the ALWR program. Therefore, insufficient information regarding the design details is known to support development of modular construction.

Major construction activities for the System $80+$ plant consider a number of innovative approaches to construction methods and procedures that are based on the need to meet the EPRI URD construction schedule. The plan calls for a team of construction technology specialists to be established to further develop initial concepts and proposed applications for these advanced construction techniques, and to coordinate these planned construction practices with plant design groups to ensure that design features and details accommodate the innovative methods proposed. All of the innovative construction methods have been successfully implemented on previous nuclear power plant projects.

The construction specialists continue to be actively involved in the further development of innovative construction methods during preliminary and detailed design phases by participating 
on design review teams for Constructability, modularization, transportation, procurement, and support facilities. In addition to ensuring the inclusion of Constructability issues and the integration of innovative construction methods in the development of the final design, these review activities also support the continued evolution of the construction plan.

Examples of advanced construction methods proposed for use in construction of the System $80+$ plant included:

- Vertical (open top) installation and placement of major equipment and large modules with heavy lift capacity cranes.

- Practical application of modularization reflected in an optimum mix of modularized equipment assemblies, offsite prefabrication, and on- site pre-assembly of major components

- Optimum use of semi-automatic and advanced welding methods

- Use of selective shop prefabricated/pre-assembled and tested electrical and mechanical equipment modules

- Utilization of structural steel and metal deck for elevated slab construction to minimize the need for temporary shoring

- Use of selective pre-cast concrete elements

- Use of selective pre-assembled reinforcing steel curtains for wall panels, columns, and foundation slabs

- Use of pre-assembled metal pool liner/wall forms

- Use of pre-assembled gang form systems for concrete wall placements

- Use of jump form and other specialized form systems where schedule reduction and cost savings can be achieved

- Use of super plasticized concrete where applicable

- Containment vessel pre-assembly and erection

- Use of bar thread couplers for mechanical rebar splices

- Extensive utilization of the site's heavy load pier to receive oversized modules/preassemblies and bulk materials, including concrete, aggregate, and sand

- Use of pre-assembled rebar modules where critical path schedule reduction and cost savings can be achieved

- Design and use of internal support frameworks for base slab and building wall materials, i.e. rebar, embeds, penetrations

- Computer design modeling and work schedule development/ presentation

- Formed backfill of excavation with lean concrete for perimeter access to the plant buildings and to provide exterior form of outer building walls

- Structural steel platforms/trestles for perimeter at grade access to below grade construction area

- Computer programs for material procurement and storage control

- Fabrication of large bore pipe spools at offsite and/or onsite fabrication facilities

- $\quad$ Pipe designs to reduce welding through pipe bending processes

- Integrated Constructability review program

- Building construction sequencing to support early start of electrical and mechanical system installation 
- $\quad$ Craft productivity programs and initiatives

- Material handling and construction access coordination

- Onsite high output concrete batch plants

Materials and construction detail standardization where possible

\subsubsection{Construction and Startup Schedule}

The baseline Construction and Startup Schedule has been completed. The schedule represents the baseline schedule developed for System 80+ construction. The Primavera P3 format permits the DPCIT cycle improvements to be incorporated and evaluated for their effect on the overall cycle. The schedule contains approximately 3600 activities and milestones, representing a Level 3 detail schedule.

The resulting baseline construction and startup schedule for the baseline is 74.5 months from beginning of project to commercial operation. The 21-month period before first concrete is based on a first-of-a-kind project. The period from first concrete to fuel load is 47 months. Table 4.1-1 provides a comparison of major milestones between the proposed Lungmen schedule and the current System $80+$ construction schedule.

Table 4.1-1

System 80+ and Lungmen Schedule Comparison

\begin{tabular}{|l|c|c|}
\hline \multicolumn{1}{|c|}{ Milestone } & \multicolumn{2}{|c|}{ Months from First Concrete } \\
\hline & Baseline Schedule & Lungmen \\
\hline Start Project & -21 & -21 \\
\hline First Concrete & 0 & 0 \\
\hline Set SCV Dish & 5.5 & 5 \\
\hline Set Reactor Vessel & 23.5 & 23 \\
\hline Cold Hydro Test & 43 & 42 \\
\hline Start Fuel Load & 47 & 49 \\
\hline $\begin{array}{l}\text { Commercial } \\
\text { Operation }\end{array}$ & 53.5 & 55 \\
\hline
\end{tabular}


Evaluation of the baseline schedule indicates that the critical activities are the completion of the reactor building interior concrete. The interior concrete includes the equipment foundations for the reactor vessel and steam generators, biological shielding around these components, the refueling cavity, floors up to and including the operating floor, the steam generator shield walls above the operating floor and the polar crane wall.

The reactor building interior concrete work cannot be started until the steel containment vessel dish (bottom section) has been installed. Installation of the dish requires completion of the sub-sphere concrete structures that support the dish. The sub-sphere, in turn, requires that the basemat is complete prior to starting the sub-sphere concrete.

Installation of the reactor vessel and steam generators follows the completion of the interior concrete to the operating floor and the steam generator shield walls. The polar crane wall is the last interior concrete to be completed. The walls must be completed before the polar crane can be installed on the rails attached to the top of the wall. Since the polar crane is installed over-the-top, through the open steel containment vessel, the vessel dome can not be positioned until the polar crane is installed.

A significant reduction in plant construction and maintenance costs is achieved by implementing data communication networks within and between the various Nuplex $80+1 \& C$ systems. This greatly reduces the quantity of hardwired signal I/O interconnection cables with a corresponding decrease in the number of required cable trays.

An additional advantage of schedule flexibility and reduction is achieved by using hardware that can be installed and terminated early in the construction schedule, even before all system functional requirements have been finalized. Software-based systems are shipped early with representative software to allow installation and preliminary checkout. Final software installation and functional testing is conducted at a more convenient point in the construction schedule. This design philosophy can significantly improve plant construction schedules for I\&C systems. Since I\&C requirements are often not finalized until late in the plant design schedule, this can help significantly to reduce costly delays.

\subsubsection{Productivity Model Construction}

The construction schedule can be developed at a Level 3 detail early in the design process. This allows evaluation of the design by construction experts and planners. The coupling of the three-dimensional plant design model (Product Model) with the construction schedule (Productivity Model) through the use of four-dimensional visualization will further result in cost and schedule improvements. Four-dimensional visualization unifies the Product Model (three-dimensional plant design model) with the Productivity Model (construction schedule). This unification permits the visualization of the construction sequence.

Construction has a different view of the plant than the engineering design view. Where as the design personnel tend to look at the plant in terms of systems and complete structures, the construction personnel tend to view the plant by areas and rooms. The three-dimensional models built for design functions are not easily used directly for construction schedule 
viewing. A critical aspect of the four-dimensional visualization is to have the ability to depict the three-dimensional engineering design model in a form necessary to understand the sequence of construction activities. It is highly desirable to have the means to transform the engineering design model into a construction model without requiring the design model elements to be modeled based on the construction sequence. This allows designers to work with a format most convenient for them while allowing the construction staff to work with the same model in a form that best satisfies their unique needs. The ability to keep the construction and design models synchronized as the plant engineering evolves is of paramount importance. The Schema feature, described in Section 4.3, provides a method of depicting the product model as a construction model.

As the plant design and construction schedule are developed, periodic reviews provide the construction input necessary to ensure the plant can be built in a cost effective manner. These reviews will occur a time when the concerns and experience of the construction experts can be factored into the plant design. The practicality and completeness of the schedule can be verified well in advance of the commencement of construction. Integration of the supply management data will ensure that material is available when it is needed, thereby reducing delays caused by shortages or increased costs due to the storage of material for long periods of time.

Alternate construction sequences can be generated in the four-dimensional visualization to evaluate cost and schedule savings for the alternate methods. As the use of large prefabricated modules is increased, the ability to plan and verify accessibility to the final module location will become increasingly important to the project planning. The visualization can assist in performing these verifications. As construction proceeds, the ability to plan work arounds for delays is necessary to ensure the overall schedule objectives can be met. The visualization allows the trial run of the work arounds prior to their execution in the plant.

The four-dimensional visualization can assist in the day to day construction activities. The state of completion of the area and room at a specific time in the sequence can be viewed by the construction engineers and supervisors. This allows a better understanding and allows more thorough planning of upcoming activities. The four-dimensional visualization has the facility to display temporary structures and equipment. Scaffolding and temporary power supplies can be displayed. The incorporation of these construction items ensures the needs are identified and planned in advance.

Integration of "intelligent" plant schematic diagrams, such as, P\&ID's and wiring diagrams will assist construction and start up activities. Progress on construction can be recorded using the visualization tool linkage to the schedule. The status can then be displayed on the schematics to monitor system completion. Start up planning can be performed using the schematics to identify system and sub-system testing. The linkage to the plant model allows display of the equipment location in the plant. This ensures the physical location of an item, such as, a valve is known prior to commencement of a test. Any special access requirements are identified and planned in advance

The use of logic networks and Gantt Charts to develop construction and project schedules is a commonly employed method use for project planning. Scheduling software, that uses the duration of the various activities and their relationships (logic) to determine the critical path 
for the project is a well understood technique. However, these software programs evaluate the data only in the dimension of time.

The emergence of three-dimensional models of the plant structures and equipment in recent years presented the possibility of further increasing the understanding of the threedimensional model (Product Model) in terms of the construction and startup schedule (Process Model). It was anticipated that the insight gained from developing a visual representation of the Product Model combined with the Process Model would assist in the evaluation of the DPCIT cycle and lead to improvements in both the construction process and the plant design. As a result, a four-dimensional software Application was developed and implemented for use in the evaluation of the Process Model.

The application is built upon the Construction Systems Associates (CSA) Incorporated 3Dmodeling application, PlantCMS. The schedule interface to PlantCMS is a CSA developed application, PMVision. PMVision integrates the schedule activities with the model objects in the 3D model. PMVision also communicates, via import and export functions, with a commercial grade scheduling application such as Primavera P3. With this organization, the initial schedule is created in scheduling application and exported to PMVision in spreadsheet format. The schedule activities are linked to the appropriate model objects either automatically or manually. At this point, 4D-construction sequence visualization and evaluation can occur. 


\subsection{Task Y-1.2 Develop DPCIT Metrics}

\subsubsection{Task Y-1.2 Approach}

This task was developed to drive measurement development that would be useful in either assessing the benefits of proposed changes in practices or for use in the assessment of an ongoing project. Adoption of various improvement tactics suggested that measures related to these improvements also be adopted. The goal in this task then is to provide a measurement development cookbook with a set of suggested measures.

\subsubsection{General Measurement Development Methodology}

In general, metrics are derived from best practices such that the measures are linked to strategic goals. Financial and non-financial Information is integrated to permit assessments that effectively balance cost management concerns with production and quality concerns. The goal of any measurement development is to avoid creating measures that drive the organization's management to sub-optimize the overall process due to a failure to consider the overall goals of the project.

Project measures should be made relevant to the level of the organization acting on those measures. Thus, while overall measures of schedule and cost performance are indeed the way to ensure the entire project is within bounds, there is a need for measures at appropriate working levels. Measurement ownership should be clear and unambiguous as well as what will be done when the measurements indicate that performance is not adequate. In other words, it should be clear to management and worker alike what must be done to alter the measurement. Thus, measurement or display of variables not under the control of the project team is irrelevant and misleading. While there is the natural tendency to try to couple everyone on site to specific goals like safety performance, the project performance measurements need to be targeted to the specific work crew or construction trade. These measures might also then be used to validate the initial project assumptions about productivity that formed the bases for the cost estimates. Therefore, rechecking these critical assumptions is indeed a suggested mechanism for aligning the ongoing project performance with the project plan. In summary, metrics are:

- tangible

- measurable

- independent variables rather than dependent variables

- connected to actions at the level of performance for individual control

- connected, but not necessarily rolled up, to the overall project goals

- few in number for any given working group or team (less than eight) 


\subsubsection{Measures of Quality}

Quality improvement programs and quality measurements have been adopted in the United States starting in the 1980's when domestic manufactured goods' market share was being lost to imported goods and the assessment was made that the imported goods had a better quality in terms of their reduced repair rate and better fit and finish. In response, statistical process control (SPC) measurements as defined by Deming and Juran have been adopted for production line facilities. While the construction of each nuclear plant does not resemble a production line from the face of the problem, there are a large number of repeated operations associated with piping systems and electrical installations that would merit a review using SPC technologies.

For a construction project overall, there are a general level of quality measures that do not require the SPC technology to adopt. These are measures of quality expressed in terms of the use of resources. The following measures are recommended for implementation:

- Cycle time

- Waste

- Rework

Cycle time is a measure of how efficiently the resources are being used. A longer cycle time indicates that more labor and energy is being expended to achieve a result. Thus, longer cycle times might indicate a need to improve the quality of the process. Wait time is embedded in cycle time and to some observers "wait time" might be construed as a nocost item and thus unfairly penalizing an otherwise adequate process. Project management research has shown to the contrary that wait times introduce coordination costs that become substantial. Therefore, wait times constitute a cost element and will be regarded with the same oversight as personnel errors.

Waste shows up in many forms. Energy is routinely wasted on job sites moving material from place to place to place. Workers not at the correct location to start a task are wasting time. The use of excessive materials and their subsequent disposal costs constitutes an obvious source of waste. While there are certainly a set of scrap dealers willing to handle excess materials from a project, there is a tremendous waste in having purchased the excess material in the first place, maintained that excess material in an inventory control system and finally realizing that the material requires some formal action to permit it to be removed from the site. None of the afore mentioned actions constitutes any value to a project and indeed diverts management attention from the completion of the project.

Rework shows up in many forms. Some forms are easy to observe when an item fails inspection after welding. Other forms of rework are more subtle when a design has to be redone several times before it is issued to the field for construction. Rework can therefore reflect the quality of the personnel, the quality of their training for the tasks being performed and the quality of the procedures and management guiding their actions. 


\subsubsection{Measures of Production}

Measures of production related to the DPCIT cycle have been identified. The assumption involved at this point is that the design was completed prior to receiving a plant order such that only the remaining customization of the design to the specific site chosen needs to be accomplished. All other categories are assumed to be starting from a zero percent complete status at the time a plant is ordered. The measures suggested below represent a starting point for the DPCIT project in providing a framework for adopting additional measures in the remaining two years of the project.

- Design

Percent of site specific design complete

- Procure

Percent of long lead time components ordered

Percent of remaining components ordered

- Construction

Yards of concrete poured

Feet of piping installed

Feet of cable pulled

Feet of cable trays installed

- Installation

Percent components installed in place

Percent components connected electrically

Percent components connected mechanically

Percent components connected to instrumentation

- Testing

System Flush/Component Checkout

System Testing/Integrated Testing

Fluid Systems Flushed

Fluid Systems Check out Complete

Fluid Systems Hydrostatic Tests Complete

Fluid System Accepted by Operations

Electrical Systems Energized

Electrical Systems Accepted by Operations 


\subsubsection{Measures of DPCIT Project Impact}

The DPCIT project has selected the book Measure Up! How to Measure Corporate Performance by Richard L. Lynch and Kelvin F. Cross (ISBN 1-55786-718-6) as the basis with which to evaluate potential project cost saving concepts. The problem now is to relate the recommendations of this book to the design and construction of a new nuclear power plant.

Figure 4.2-1

The Performance Measure as part of a Feedback Loop

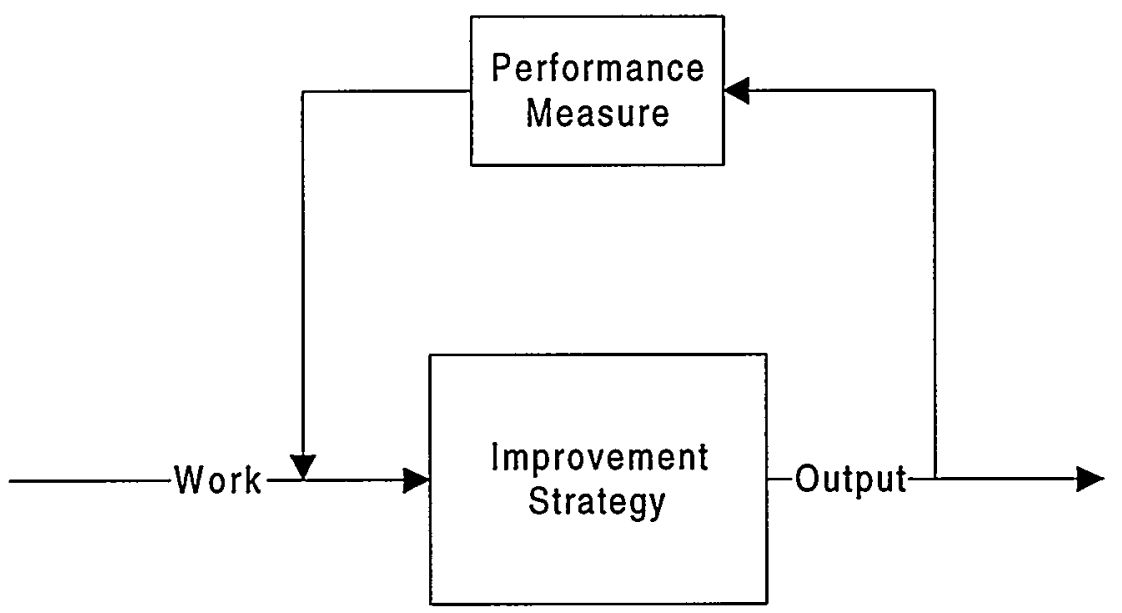

Lynch and Cross draw the analogy of the performance measure as a part of the classic control system depicted in Error! Reference source not found.. To improve a system's output, define the improvement, measure it, and feed it back into the system. To Lynch and Cross, the output needing refinement is the performance improvement strategy.

The Lynch and Cross book describes the process one uses to arrive at these performance measures. Their approach begins with management, who establishes a corporate vision. This group and their subordinates then identify and map core processes of the business. Based on this mapping, management identifies key strategies to improve and reshape the core processes to fit the corporate vision. It then becomes the responsibility of department level management and supervision to develop tactics to implement the strategies. In this context, tactics are defined as those day-to-day relationships and processes that make a high level strategy like Just in Time supply systems work. Performance measures that gauge these tactics provide feedback on the strategies' effectiveness.

The conceptual nature of this study makes complete adherence to the Lynch and Cross process difficult. The authors intend their process to modify existing corporate structures. This effort's basis is the design of a new one, so no structure exists. This lack of structure makes it impossible to map key core processes and establish real tactics for improvement. Consequently, the sequence here must differ slightly from that described above. For 
similar reasons the product will also differ slightly from that proposed by the author. Figure 4.2-2 shows the new proposed sequence. Instead of revisions, the process metrics effort will produce a set of original project procedures and a new proposed project organization (structure). The exercise will use the mapping process recommended by Lynch and Cross as the design methodology. The resulting roadmap will have sufficient detail to allow rapid implementation when the next nuclear power plant project goes forward.

As stated above, Error! Reference source not found. illustrates the proposed sequence for further study. The corporate vision exists, as does the list of core processes. Error! Reference source not found. contains the list of potential cost reducing strategies. The next step involves selecting from this list. Next year's activities will include activities to rank and refine the potential strategies. With the culled list, the plan is to spend year three sketching process maps and writing supporting documentation to incorporate the strategies into a project organization with project procedures. From these project procedures come the tactics available to project participants to reduce costs. From these tactics comes a final list of project performance measures.

Figure 4.2-2

\section{Relating the Lynch and Cross Process to This Conceptual Study}

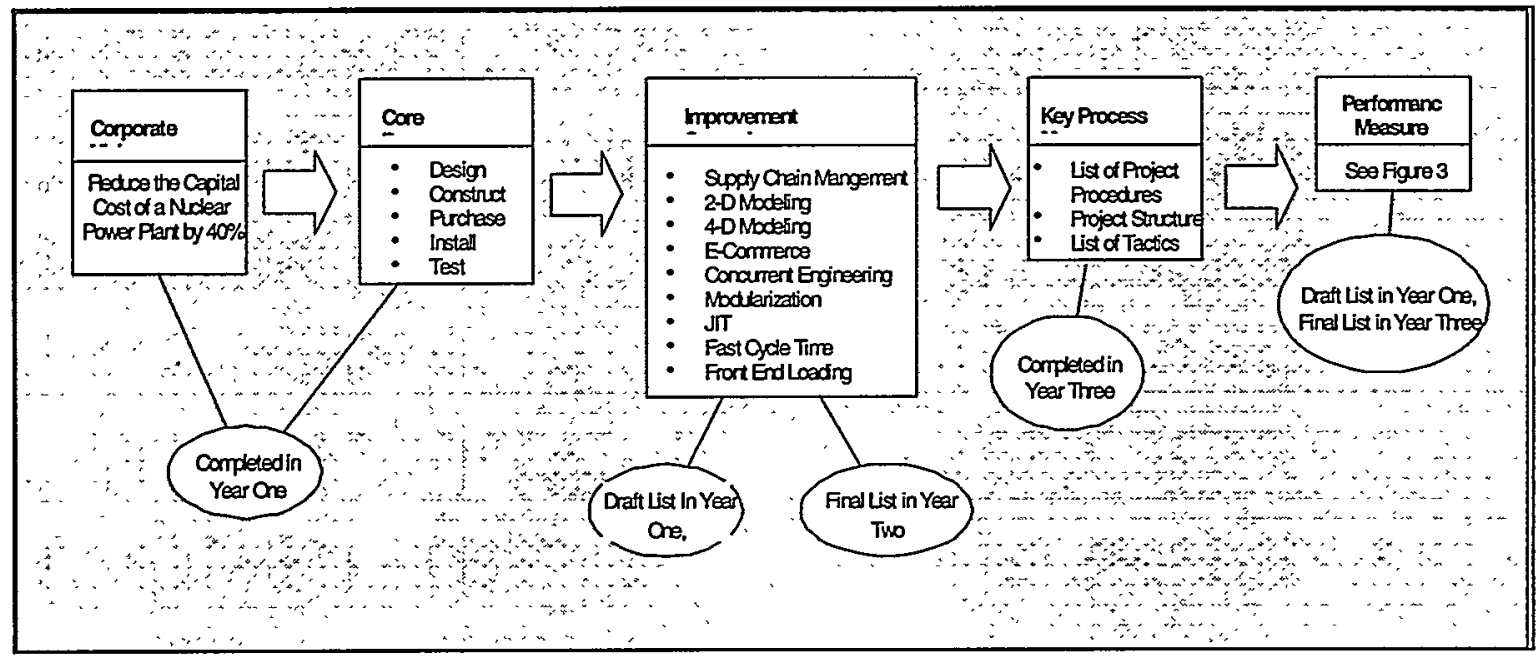

\subsubsection{Proposed Measurement Categories}

Figure 4.2-3 contains a map between strategies and performance measures. It is included to illustrate the feedback link between strategies, their implied tactics, and desired goals as presented by Lynch and Cross. The fact that the tactics are implied limits the validity of the measures contained there for now. However, the matrix was developed as a way to move conceptually between the high-level management theories of Lynch and Cross and the dayto-day effort of making a project work. It has proven to be an excellent tool with which to 
illustrate that relationship to others, and is included here for that purpose. This tool will have other functions in the future. This matrix will help next year in mapping performance measures to potential capital cost impacts. In addition, it will serve as a means to communicate the progress of the ranking and refining process on strategies, and the development of tactics as they emerge from the process of mapping project organization and procedures. 


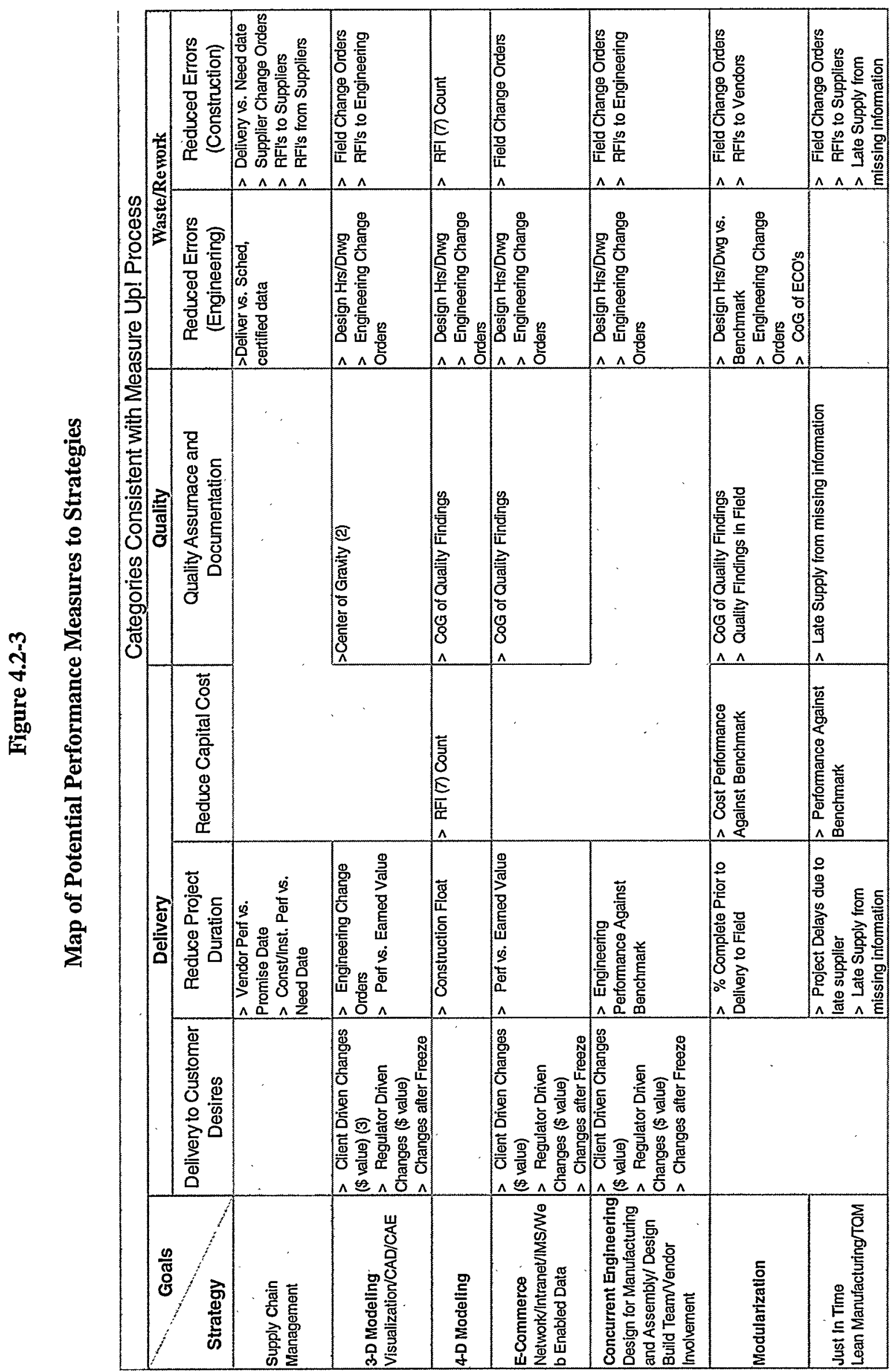


Notes on Figure 4.2-3

1. This paper assumes that reduced cycle time refers to the complete amount of time from initiation to conclusion of an activity.

2. Center of Gravity for Quality Findings. The tactic here is to find errors as early as possible in the DPCIT process. A flaw found in a fabrication at the construction site is much more expensive than a flaw found in the factory. This measure indicates success when the Center of Gravity is as close to the start date as possible. The term "Quality Findings" needs more definition. It should include inspectors reports of adverse findings, radiography, qualification tests, and/or any other document that provides indication of the quality control process in action.

3. Client Driven Changes. The tactic here is to involve the client(s) early in the job to pin down changes before they become expensive. The term client applies to several different groups including the utility company building the plant, the issuers of nuclear permits, the issuers of environmental permits, the issuers of zoning permits, and others not yet named. This particular measure has a time dimension also. Decisions regarding the basic power generation process must occur during the conceptual design phase, but decisions regarding the color of paint for the manager's office can wait until the construction phase.

4. Performance against Benchmark. For now, this term is used as a generic description of a measure that uses an outsider reference to gauge performance.

5. Fast Cycle Time. Fast Cycle Time actually a combines Supply Chain Management, 4-D Modeling, and Just in Time, as evidenced by the similarity of performance measures.

6. The term ECO is an acronym for Engineering Change Order. ECO's provide a means for engineering to implement a change to the original design subsequent to issue. ECO's are valid work authorizations.

7. The term RFI is an acronym for Request for Information, a sequentially numbered message used typically to communicate questions between construction and engineering, construction and purchasing, and engineering and supplier. Project procedures usually require formal closure of all RFI's before a project can be closed out. On larger projects, this may be implemented at a WBS level. The RFI is not an authorization to do work. 


\subsection{Task Y-1.3 Develop 3D/4D Model of Base Plant}

\subsubsection{Task Y-1.3 Approach}

A three dimensional model of the System $80+$ plant was taken from earlier ALWR program work performed by DE\&S in the early 1990's. This model was originally created in EA Systems PASCE product. For the purposes of the work for this NERI project's Productivity Model, the 3D model is combined with the timeline of assembly activities to create what is commonly known as a 4D model. The 3D model stands alone and is used as a design tool for the classic resolution of design issues, while the $4 \mathrm{D}$ model offers new possibilities for examining how a power plant is actually assembled.

A Four-Dimensional (4D Visualization) of the System 80+ Advanced Nuclear Power Plant was developed to assist in the development and verification of the construction schedule. As the visualization was developed, the tools and methods used were evaluated. The PMVision commercial software application from Construction Systems Associates, Inc. (CSA) was selected to provide linkage between the System $80+3 \mathrm{D}$-computer model and the construction schedule database. With this linkage, a time dependent computer screen display of the plant 3D model is generated. That display, or 4D visualization, is then used for evaluation of construction sequences to identify construction bottlenecks, construction plan problems, correct the problems, refine the construction plan, and explain the overall System 80+ construction plan.

Significant benefit resulted from the use of the PMVision 4D-visualization application. The benefit was to be able to verify that its overall System $80+$ schedule was reasonable, identify and correct logic errors in the System $80+$ schedule, and isolate and evaluate critical construction and installation sequences. Although the System $80+$ schedule duration is essentially unchanged, the confidence in the duration is greatly increased because of the errors identified and modifications made by use of PMVision.

\subsubsection{D/4D Expected Benefits}

An important consideration in the development and use of the four-dimensional visualization is the ability to relate $3 \mathrm{D}$ model objects to the schedule activities. The relationship between a model object and a schedule activity must be easy to define and persistent to minimize data re-entry as the model or schedule are modified. As an evaluation tool, the ability to modify these relationships with ease is a necessity.

The benefits of the use of a computerized 3D for plant design is well established. The 3D model also provides a significant benefit for plant constructability, if the model is effectively integrated into the planning process. In the preliminary design and detailed design phases of the project the model, coupled with the construction schedule development, can be used to improve the constructability of the plant. These tools can be used during the construction phase to improve the work processes to reduce the overall construction time. 
The uses of the 3D Model and construction schedule can be categorized into 3 classes of increasingly more complex functionality as follows:

- Visualization:

The ability to examine and query a realistic graphical (i.e. 3D) representation of the Plant, including various design alternatives. A four-dimensional visualization provides the additional ability to conduct the examination of the plant as a function of project time by linking the 3D Model with the plant construction schedule. This visualization assists in selecting design options that will have the most desirable affect on the construction schedule.

- Virtual Prototyping:

The ability to activate or manipulate a computer model of the plant to assess construction performance by conducting expected operations and actions within the model. This will validate the application of the use of modular construction and other innovative techniques to ensure that the interfacing conditions are properly addressed. Changes in sequence and temporary interferences can be determined and planned for prior to the commencement of the actual construction.

- Project Process Simulation:

The ability to execute real time processes on the computer model based on an established environment and variable inputs to obtain real time predictions of the outcome. Installation rates and manpower requirements can be verified in more detail. The need for temporary structures and services in the plant during construction can be determined and scheduled to a higher degree of accuracy. The potential uses of this functionality for new nuclear power plant construction and specifically in the development and application of modularization is discussed below.

From the model, physical characteristics (quantities, materials, etc.) of modules can be assessed and differences in the construction and fabrication schedules and sequence scrutinized and optimized. Major construction projects require the creation of a variety of schedules ranging from level 1-showing major construction activities and milestones, to level 5-representing full construction and erection details. These schedules represent thousands of activities, which require a major effort to identify and scope. Scheduling software that provides the timing and sequencing of these activities can then be linked with the model to provide a time dependent or $4 \mathrm{D}$ visualization of the construction schedule. This visualization provides:

The interface can be a very simple visual representation of the schedule or it can be implemented as an effective tool to create and manage construction scheduling activities. By applying these techniques to modularization and innovative construction techniques, reduced critical path construction schedule duration can be assessed. Modularization's greatest benefit is saving time during the construction phase. The highest program priority will be assigned to those activities that directly compress the overall project critical path schedule by 
de-coupling sequential activities and creating parallel work. Attention is directed specifically to sub-critical path construction activities that could become critical if their duration should increase, or if the project critical path duration is shortened.

Virtual prototyping, the ability to activate or manipulate a computer model of the plant to assess performance by conduct expected operations and actions with the model, is coming into significant usage for product development in the manufacturing industry. Since Modularization is essentially a move to "manufacture" rather than "construct" the potential benefit should be applicable. Virtual Prototyping of the selected module can be used to construct a physical (3D) and logical (schematic) "mock up" of the module. From this point, engineers can define the interfaces and animate the transportation and installation to confirm viability. Modularization requires more engineering information, more front end engineering, more drawings, and earlier working drawings to fabricators. Structural design effort is also increased due to transportation loads and critical module interfaces. Module transportation including transportation scheme, transportation load stress design, route surveys, specialized transportation and handling equipment must be considered. Additional materials are required for transport and handling bracing. Module bases and frameworks may also be necessary. Multiple suppliers of materials to one or more fabrication locations requires additional procurement effort to support the increased complexity of routing and tracking materials to multiple locations. Extra effort and additional drawings are required to precisely locate all components and insure dimensional tolerances are maintained. Since any rework required at the site can be twice as expensive in terms of cost and schedule the benefits of considering all these factors in a virtual prototype are obvious.

\subsubsection{Construction Modeling Results}

Considering the moderate level of detail available in the System $80+$ construction schedule and $3 \mathrm{D}$ model, the construction sequence, critical path, and overall schedule presented by the $4 \mathrm{D}$ visualization is valid and provides a reasonable basis for establishing potential investor confidence. During the 4D-application development and evaluation, however, several areas needing further examination and potential improvement were identified. Some of these areas include:

- the application stability when running in a multi-user environment,

- the ability of the application to process the large amounts of $4 \mathrm{D}$ application data,

- the need to manipulate the schedule directly from the PMVision application, and

- $\quad$ the need to improve user operating instructions and on-line help.

An important observation is that the level of detail in the System $80+3 \mathrm{D}$ model is different from the level of detail in the System $80+$ construction schedule. To accommodate these differences a linking strategy was developed for matching the related schedule activities with their 3D model objects. In addition, a schema approach described below was developed to create the 3D-construction model from the 3D-design model. This method also permits construction model modifications without impact on the design model. 
During development and use of the 4D application, several insights were gained. The design certification work did not include unique numbering or identification of equipment. This is required to match the $3 \mathrm{D}$ model objects with the schedule activities. Work package numbering was adopted to the schedule and implemented in the converted 3D model. This technique permits addressing changes in equipment status such as installed, construction test, or startup test. Construction test and startup test activities were integrated with the construction schedule to give a more complete and realistic evaluation of the schedule duration. Increased detail in the $3 \mathrm{D}$ model will permit more accurate depiction of scheduled construction/installation activities in the $4 \mathrm{D}$ visualization that will assist in decreasing site design engineering.

A major activity is to create an organization structure that is applicable for construction scoping of the project. Construction has a different view of the plant than the engineering design view. The 3D models built for design functions are not easily used directly for construction schedule viewing. A critical aspect of the 4D visualization is to have the ability to depict the 3D-engineering design model in a form necessary to understand the sequence of construction activities. It is highly desirable to have the means to transform the engineering design model into a construction model without requiring the design model elements to be modeled based on the construction sequence. This allows designers to work with a format most convenient for them while allowing the construction staff to work with the same model in a form that best satisfies their unique needs. The ability to keep the construction and design models synchronized as the plant engineering evolves is of paramount importance.

The visualization techniques can also be used to assess alternate means of moving a module into location. As an example, the unitized reactor vessel head area must be moved into the reactor building. The unitized head area is a module consisting of:

- Reactor Vessel Closure Head

- Control Element Drive Mechanisms

- Heated Junction Thermocouple Pressure Housings

- Head Insulation

- Closure Head Lift Rig

- Head Area Cable Trays

- Associated Power and Instrument Cable.

Visualization can be used to check the feasibility of different options for moving the module into the building. Two options have been investigated for the System $80+$ unitized head area; over-top-installation and through the equipment hatch.

The following figures show that over-the-top installation requires placement of the unitized head area before the building dome is installed. The unitized head area will have to be protected from construction debris and will cause congestion in on the operating floor.

A conceptual design of the skid required for transport of the unitized head area was developed to establish a maximum outline of the packaged head area. This concept can be used to set the interface for the actual skid design. 
Figure 4.3-1

Unitized Head Area/Over-the-Top Installation

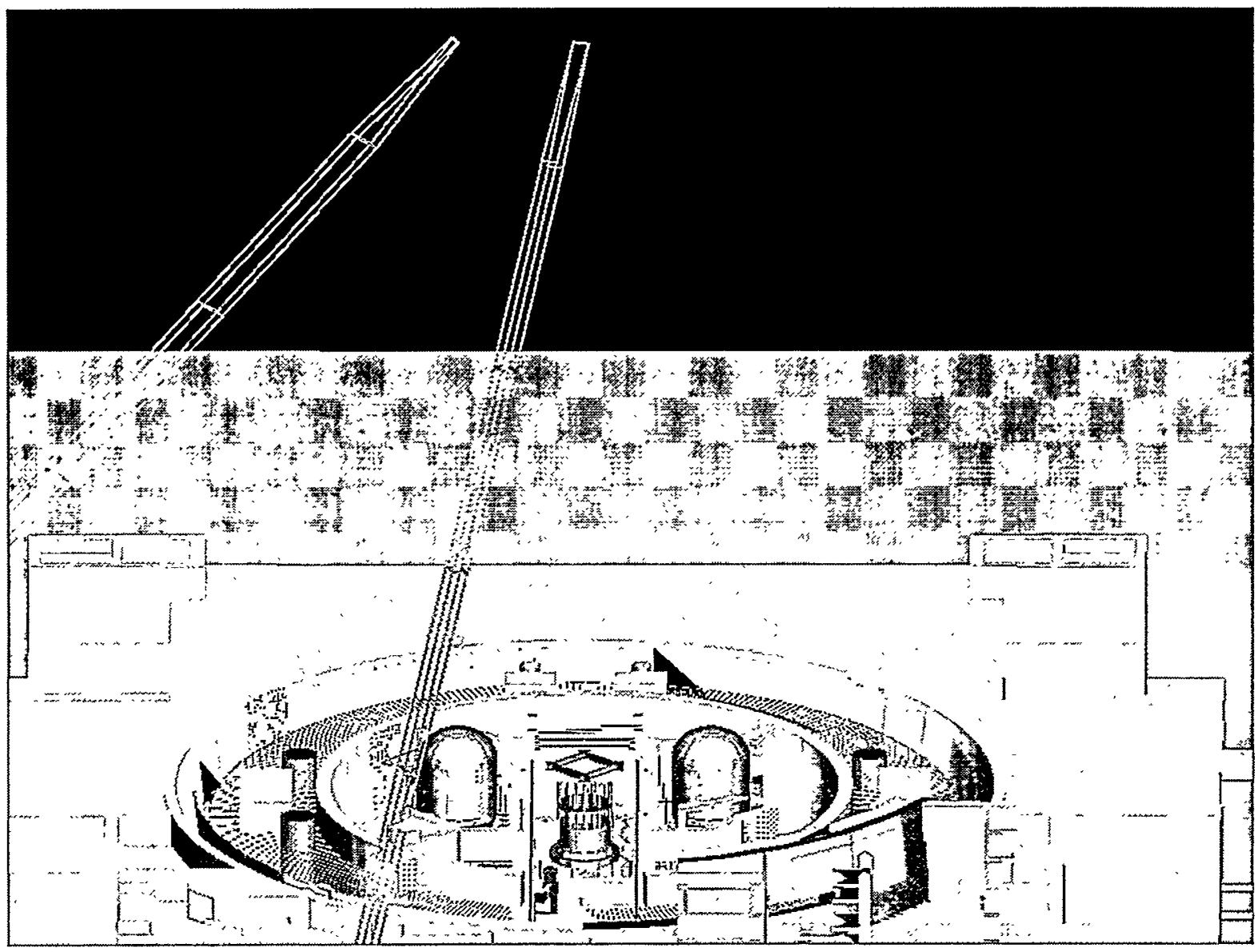

The second installation through the equipment hatch is preferable since the unitized head area can be delivered to the site later and it can be moved into the reactor building after the civil construction activities and RCS installation are complete. This reduces congestion and potential contamination of the head area.

Drawing reviews do not quickly isolate the areas of concern and provide the necessary resolutions. However, using the $3 \mathrm{D}$ model provides a tool to quickly assess the feasibility of the equipment move. As can be seen in the following figure, the major area of potential interference is the column outside of the equipment hatch.

The engineering studies of the module handling can be generated from the computer models. These movies can be attached to the IMS data base for retrieval and use by the construction staff for detailed planning of the rigging requirements. 
Figure 4.1.3

\section{Unitized Head Area/Installation through Equipment Hatch}

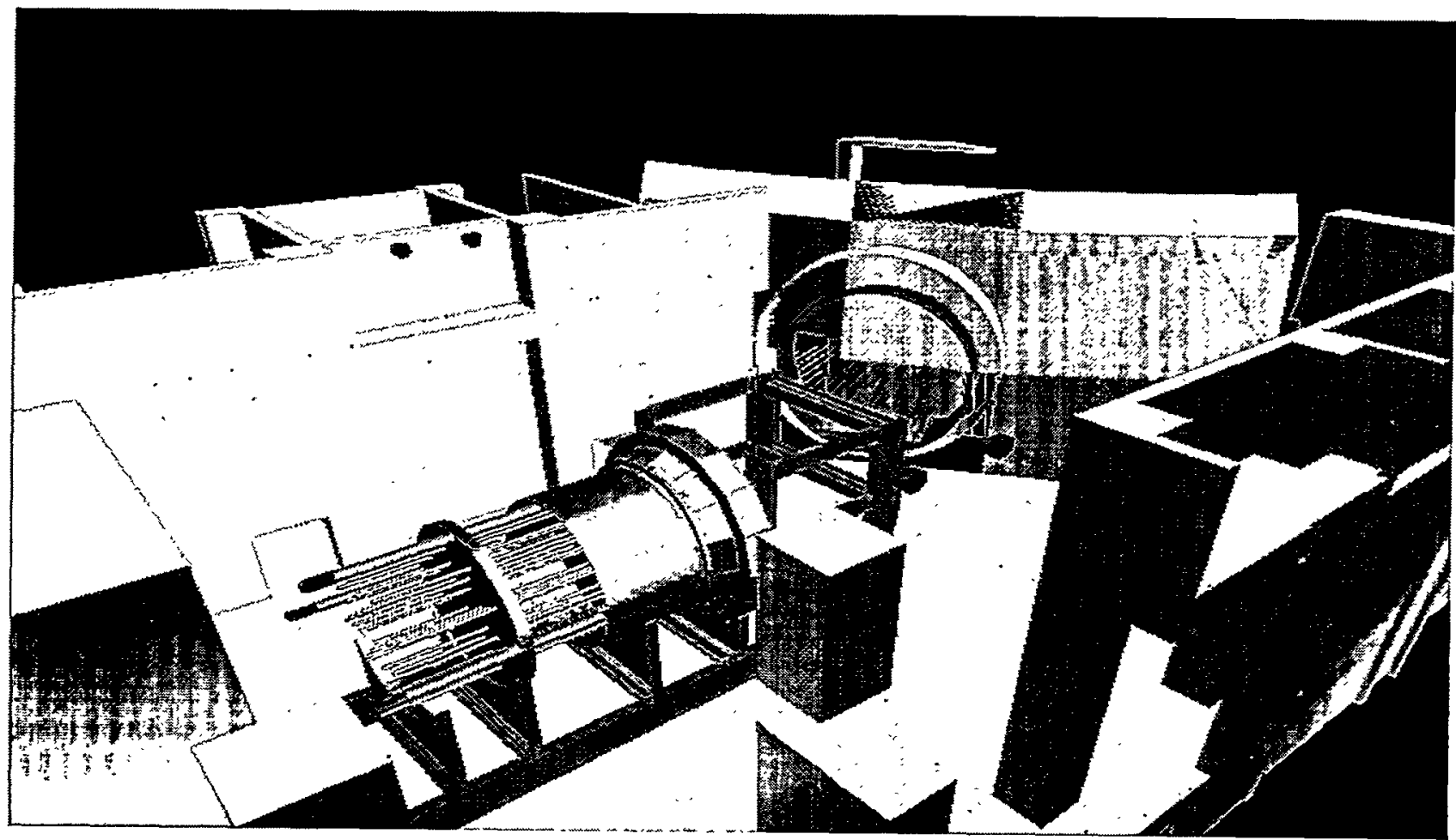

The 3D model was used to visualize the installation of a refueling pool liner module to determine handling concerns and study the design related aspects of using this type of module. Using the 4D visualization techniques, the installation can be easily checked with the building at the desired level of completion. Only the structures and components that are in place according to the construction schedule are included in the visualization. 
Figure 4.3-3

\section{Construction Progress at Pool Liner Module Installation}

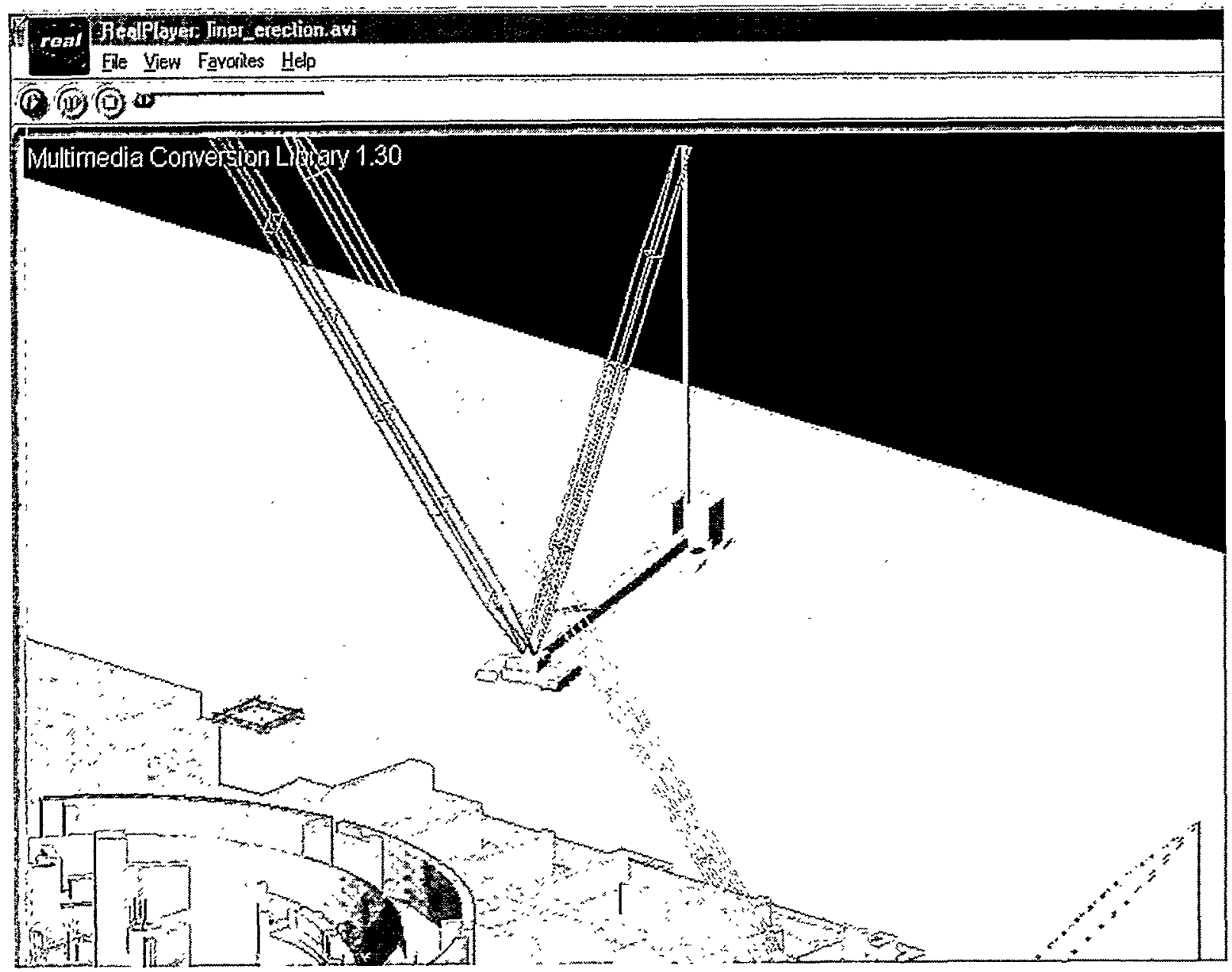

The visualization is used to assess the impact of the liner module on the construction schedule. Some of the questions that can be answered through visualization are:

- What is the best stage of construction for module installation?

- Does the module cause interferences with permanent structures or temporary construction structures?

- Are changes in design required to implement the module?

As shown in Figure 4.3-4, the attachment of the module to the floor will require consideration of the reduced access that results from the modular construction. Connection of the floor of the module to the concrete structure must be resolved by engineering before committing to the use of this module. 
Figure 4.3-4

\section{Examination of Containment Floor Modules}

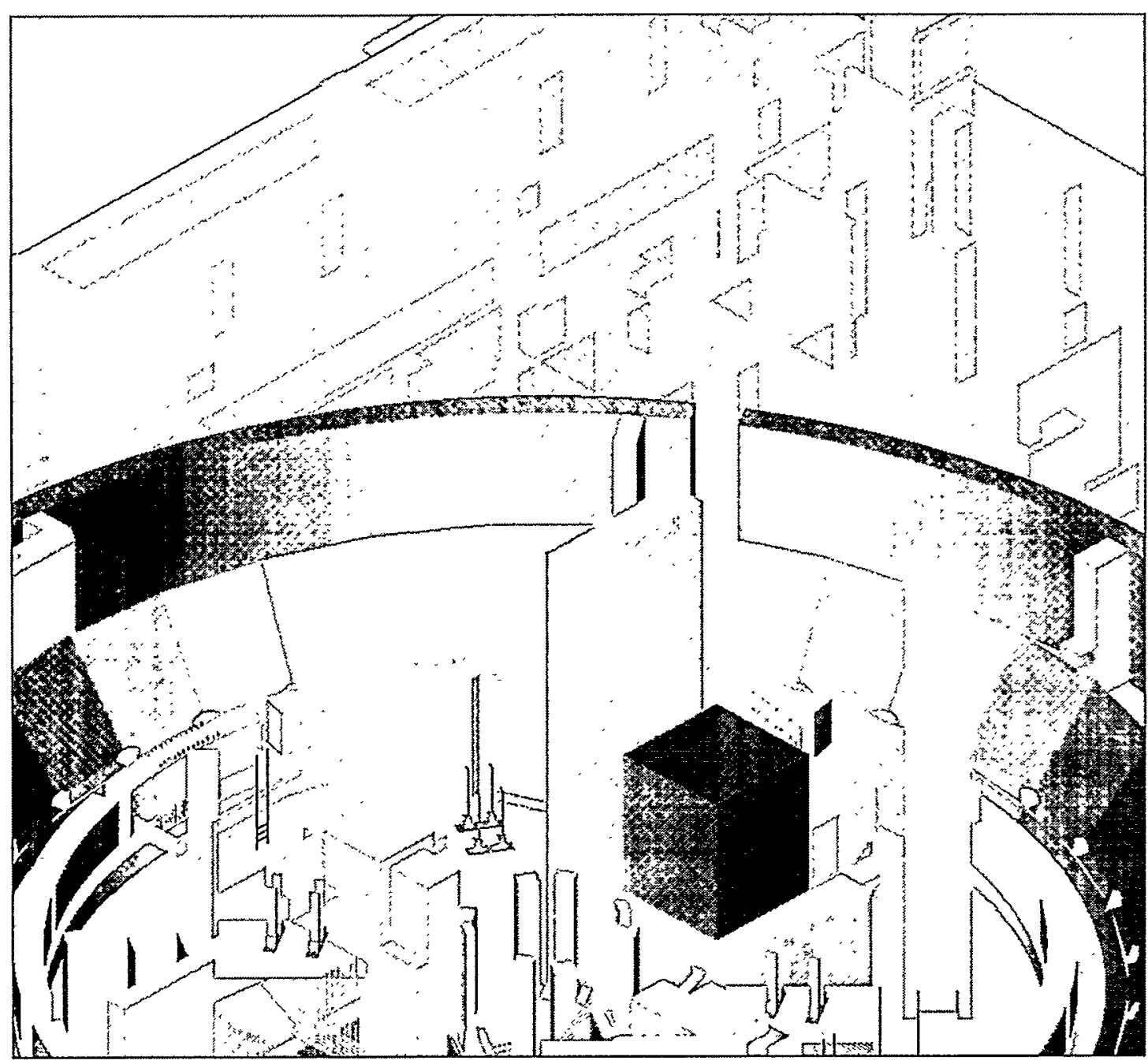




\subsection{Task Y-1.4 Research Other Industry Practices}

\subsubsection{Task Y-1.4 Approach}

A key principle in guiding the development of this project was the intention to examine cycle time and cost reductions achieved in similar scale industries. Notable improvements in aerospace and heavy manufacturing have been noted in various business articles. While the nuclear power industry has identified some methods for improvement that will address issues noted during the construction in the 1970's and early 80's, there has been no construction in the US with which to apply newer business practices. Additionally, many of the new practices found in US assembly industries have been adopted following the completion of the US nuclear power construction period. Therefore, this research task was focused on examining practices found in other industries in which the scale and magnitude are similar for a nuclear plant.

\subsubsection{Observation of Related Industry Practices}

We performed research on the work practices and principles introduced by advanced manufacturing organizations, such as Boeing and Chrysler, as well as non-nuclear manufacturing units within $\mathrm{ABB}$. By research on the work practices of aerospace, automotive and other big manufacturing organizations, a number of key approaches and tools have been identified such as New Design Tools, Design-Build Team (Concurrent Engineering), Modularization, JIT, Lean Thinking, Supply Chain Management, e-Commerce and Simplified Quality Assurance $(Q A)$ Requirement. Some of practices have reduced their product cycle times by more than $50 \%$.

\section{New Design Tools}

Boeing 777: Computer-graphics Aided Three-dimensional Interactive Application (CATIA) and Electronic Pre-assembly In the Computer (EPIC) were used in designing Boeing 777, and no mock-up is required. 3-D design enabled the new plane to be delivered on schedule and on budget.

A Pilot Plant for Sequus Pharmaceuticals: By integrating 3D CAD design with scheduling and cost programs, the plant project team traded small increases in design time for greater productivity during construction. The piping and mechanical subcontractors had far greater productivity and virtually no rework.

\section{Design-Build Team (DBT), Concurrent Engineering, \& Modularization Approaches}

Boeing 777: "Working together" management strategy and the revolutionary DBTs have been applied for Building Boeing 777. With DBT working method, errors were reduced by $95 \%$.

As a virtual management primer in coordinating the work of thousands of professionals, more than 200 DBTs, each including a senior design engineer, a manufacturing supervisory, 
a financial manager, and (frequently and interestingly) a representative of a customer company, worked concurrently for the design and build the new generation of passenger aircraft.

Caterpillar: Caterpillar has successfully used Concurrent Product Process Development (CPPD) to accelerate product time-to-market: average cycle time decreases from 5-7 years in Mid-1980s to 39 months in 1997. CPPD applied extranet approach and web-based tools to enable errors to be corrected before they become costly.

Just-In-Time (JIT) and Lean Thinking

Chrysler: In the beginning of the 1990's, Chrysler had 1600 external suppliers shipping materials to $14 \mathrm{car}$ and truck assembly plants to North America. By adopting JIT philosophy, plants have reduced on-hand inventory from 5 days to 48 hours and eliminated more than $\$ 1$ billion from the inventory network. Some suppliers also reduced inventory up to $75 \%$.

Lean thinking approach took a key role in cutting waste in every step and achieving the same output with half the number of workers.

\section{Supply Chain Management and e-Commerce}

Dell: Dell Corporation has frequently been cited for its assemble to order process with a consequential decrease in inventory on hand. However, it is not clear whether this shift of inventory from Dell's premises to a series of Just In Time trailer loads of material represents a true savings or merely a burden shift onto the parts suppliers.

Chrysler: Chrysler's Supply Partner Information Network (SPIN) allows 3500 of its 12000 suppliers selectively access to portions of its intranet. Suppliers can continually monitor product requirements, scheduling, and commitments of their customers against their own schedule to ensure that enough inventory will be available. The SPIN has reduced the time to complete various business processes by $25 \sim 50 \%$.

Bidcom and Cephren: The nation's biggest construction contractors, like the Tuner Corp. and the Bechtel group, have started to use e-commerce sites like Bidcom and Cephren, which help them communicate with partners and subcontractors and even buy materials and bid for jobs. So far, in construction industry, total online business has reached $\$ 6.3$ billion.

E-construction can also enable viewing architectural drawing online and printing relevant sections straight from their computers - without wasting time waiting for the drawings to be commercially printed, packed and delivered to the scores of participants in a given project each time the plan are tweaked.

Simplify the QA Requirement

Airbus: One of Airbus Industrie's innovative approaches is to share the same parts on different models. The commonality concept reduces spare requirements and increases maintenance efficiency.

Boeing 777: Boeing applied ISO 9001 in Boeing 777 manufacturing, and simplified its business system for handling the flow of parts data by grouping the parts in three modules (a 
collection of parts, plans and tools): 1) basic and stable module: parts that are used on each airplane model; 2) available module: options for parts already engineered and delivered to a customer; 3) unique module: options or newly designed parts that have never been certified before. Therefore, a very complex system has been highly simplified, as well as its QA requirements, design and build process.

But, one of the major challenges of translation of the above-mentioned innovative practices into each part of the DPCIT cycle is that it requires a structure for adopting these new practices as well as a mechanism for understanding the interrelationships. 


\subsection{Task Y-1.5 Examine Modularity}

\subsubsection{Task Y-1.5 Approach}

Using the existing design of the System $80+$ PWR of ABB-CE, we have designated the north half of the reactor auxiliary building for analysis. Our approach is to create space frames which can be utilized to prefabricate the systems within the plant. These prefabricated modules will then be assembled at the site of the proposed power plant.

\subsubsection{Task 1.5 Results}

We have identified four module types that should be sufficient for constructing the plant. For the majority of the auxiliary building, a rectangular module will be the optimum design. To accommodate the shield and containment buildings, these modules will be modified. For the containment building itself, which is spherical, a different style of module is used. The containment will be divided in 60-degree sections horizontally. The lower half will be placed first, followed by the upper half.

There are two major factors affecting the progress of the work at this point. First, we need to address the question of how to best connect the modules at the work-site (i.e.; welding, bolting, etc.). Also, there is the challenge of modularizing the shield. The massive amount of concrete necessary for the shield poses a mobility problem for modules. There are at least two possible solutions. The first is to use steel for the material in the shield. However, we need to interview someone who has expertise in this field. The engineers at DE\&S did not have a definitive answer on the use of steel in place of concrete. The second solution is to combine the idea of modularity with the traditional method of construction. This would involve pouring the shield in parts while the rest of the plant was constructed in the modular style described above.

Modularization has been considered for a limited number of items, based on the current completion status of the design. These items are considered to have the most potential for project critical path schedule reduction and overall cost savings. These elements of modularization have not been fully factored into the baseline schedule. The items include:

- Reactor containment vessel steel plate, including dome

- Reactor vessel and internal components

- $\quad$ RPV steel pedestal and shield walls

- Basemat reinforcing steel and support assemblies

- Main control panel assemblies

- $\quad$ Steel pool liner wall forms

- Structural reinforcing steel curtains and mats

- Left-in-place steel liner concrete forms

- $\quad$ Selective pre-assembled piping, pump and valve assemblies

- Selective pre-assembled major electrical/mechanical equipment 
- Selective functional components shop-mounted on common bases

- Water treatment and radwaste systems

- $\quad$ Large pipe whip structures

- Reactor containment crane

Where it is determined to be practical and productive to modularize, the following list of items will also be considered for inclusion in the project modularization plan. In general, the modularization of these components does not result in a reduction in the 48 month construction schedule critical path. As the overall DPCIT cycle is reduced, modularization will have a considerable impact on meeting the reduced cycle time. Benefits from the current level of modularization are realized in other areas of plan objectives such as reduced site construction, reduced site risk, increased labor productivity and reduced labor congestion.

- Diesel generators and accessories

- $\quad$ Shop fabricated commodity supports (pipe hangers, raceway and HVAC supports)

- Main Steam and Feedwater isolation valve and piping manifolds

- Building area air supply system filter trains/fans

- Switchgear

- Pre-assembly and test of combination equipment modules

- FW make up water pumps and piping

- $\quad$ Pre-assembled structural frames for support of wall construction materials

- On-site fabrication of HVAC duct and plenums

- $\quad$ Pre-assembled instrument \& control packages

An important consideration for the System $80+$ modularization program is the construction of structural modules. The construction of the buildings can proceed at a more rapid pace when subsections are pre-assembled away from the plant buildings. The work is more efficiently performed horizontally at grade level with increased access for craft labor and equipment. Additionally, the next elevation or area can be started while the previous module is being placed. The benefits of structural modules have not been fully considered in the baseline schedule.

The installation of the Reactor Coolant System Components is a major activity that impacts the construction schedule. The System $80+$ plant includes modularization improvements to benefit the schedule. These improvements result in increased pre-assembly at the manufacturer's facility to decrease the assembly time on site. System $80+$ modularization was considered during the design phase and consists of the following:

- The baseline schedule assumes that installation of the reactor vessel, steam generators, reactor coolant pump cases and main loop pipe is completed, including welding, before the reactor internals are installed in the reactor vessel. This approach has been used historically to ensure the reactor internals are not affected by component distortion, and movement during the welding process. Recent studies indicate that the reactor internals can be installed during the primary loop welding. This will reduce the schedule for these activities. 
- Based on simultaneous primary loop welding and reactor internals installation, the schedule for internals installation should be reduced to take full advantage of the potential reduction. This is accomplished by increasing the level of shop assembly of the reactor internals.

- The reactor vessel internals are pre-assembled into two (2) major assemblies prior to shipment. These assemblies are the core support barrel assembly and upper guide structure assembly. The core support barrel was previously shipped as two (2) subassemblies that were field welded together after final alignment. Assembly of the core support barrel in the manufacturing facility decreases field assembly at the alignment and welding is performed under more controlled shop conditions. The upper guide structure assembly is aligned to the core support barrel assembly at the manufacturing facility further decreasing the job site work and schedule.

- The reactor coolant pumps are pre-assembled to the maximum extent possible in the manufacturing facility. This pre-assembly was successfully performed for the Yongwang Units 3 and 4 plants with a corresponding reduction in site installation time. The major elements of the pre-assembly plan are to mount the pump auxiliary equipment such as heat exchangers and reservoirs with the associated valves and piping to the motor support stand. Additionally, the seal assemblies are built up and aligned at the manufacturing facility.

- The majority of the current commercially available off-the-shelf I\&C electronics and computer equipment is provided by the OEM in modular form. For example printed circuit cards, relay modules, logic I/O modules, etc., are mounted in racks and drawers; which are then treated as replaceable assemblies in the Nuplex $80+$ cabinet and panels.

- Standardized cabinets and panels are provided for each of the major Nuplex $80+$ I\&C systems. Their internal design includes the use of connectors on modules that are expected to be periodically removed for maintenance and replacement.

- Very large cabinets and panels are designed to be transported in subsections, which upon installation are bolted together and supplied with internal pre-assembled cables with connectors for quick assembly.

- All permanently mounted I\&C cabinets and panels are provided with pre-drilled holes for bolting to floor embedments, unless welding is specifically required for technical requirements such as seismic capability.

- All instrumentation and control panels/cabinets are pre-wired at the factory. Functional factory acceptance tests are performed with all modules installed prior to shipment. Removal of internal cards or modules is minimized and done only where special precautions are needed to protect the equipment or is required by shipping regulations for special handling. 


\subsection{Task Y-1.6 Examine Upcoming Technologies}

\subsubsection{Task Y-1.6 Approach}

The task objective is to examine technologies that could assist in meeting the DPCIT goals. The focus was in the areas I\&C digital technology design and fluid systems large equipment procurement. The methodology for this task was as follows:

- Review each of the applicable codes and standards identified for application of digital technology in a generic protection grade system and determine if it has significant impact on the length of DPCIT activities.

- Consider, in view of industry maturity and technology advancement, whether the related nuclear safety goal could be met in a more efficient manner and a corresponding shortened DPCIT cycle time.

- For each potential DPCIT improvement area identified, provide a text description of the existing code or standard, a recommended change to shorten the DPCIT cycle time, and the justification basis for the change.

\subsubsection{Impacts of Upcoming Technologies}

\section{I\&C Digital Technology (Common Q)}

The EPRI co-sponsored generic qualification of common qualified PLC platform for safety related applications is being monitored to determine the feasibility of digital technology in an integrated architecture throughout the plant. The scope of the Common Qualified Platform (Common Q) Phase 2 effort is to generically qualify and license the Advent 160 Programmable Logic Controller (PLC) for Class 1E nuclear safety applications. Qualification includes seismic, environmental and Electro-Magnetic Interference (EMI) testing to EPRI TR-107330 requirements. The effort includes submission of a generic Common Q topical Report to the NRC and obtaining an approved SER. In addition, Appendices to the Topical for specific applications are also a part of the program. The systems addressed by the Appendices include: Reactor Protection System (RPS), Plant Protection System (PPS), Engineered Safety Features Actuation System (ESFAS), Core Protection Calculator System (CPCS), Post Accident Monitoring Systems (PAMS) and the Integrated Solution which addresses a total I\&C modernization approach. The Common Q Phase 2 program was completed in December of 1999.

The CEOG and EPRI authorized Westinghouse Electric Company to begin the Common Q Phase 3 program in January 2000. The Phase 3 Common Q program scope includes the qualification of various system support hardware such as power supplies, flat-panel display systems, fiber-optic modems, etc. necessary for specific Common Q system applications as 
identified in the Appendices to the Topical. The Human-Machine Interface (HMI) and generic software will be developed for PAMS and CPCS applications. The Advent PLC and support equipment required to prototype the protection system single channel has been ordered.

\section{$\underline{I \& C}$ Licensing \& Design Standards}

The maturation of the nuclear industry in general, and of Instrumentation \& Controls (I\&C) technology in particular offers the opportunity to consider novel, more efficient approaches to meeting nuclear safety goals which may not have been appropriate or conceivable when industry codes and standards were first developed.

Reviews of domestic I\&C codes and standards in light of industry and technology maturity have been completed. Recommended changes to requirements or interpretations that will support a shortened Design, Procurement, Construction, Installation, and Testing (DPCIT) cycle for the Generation 4 Reactor Program have been documented.

\section{$\underline{I \& C}$ Technology Advancements}

In the years since the last domestic Nuclear Power Plants (NPPs) were constructed, great advances have been made in Instrumentation \& Controls (I\&C) and Human System Interface (HSI) technologies. These advancements have been fueled by the accelerated development of digital computer and communication technologies. To date, NPP deployment of digital I\&C technology has been limited to upgrading of individual systems and constrained by the original plant infrastructure. New NPP construction would afford the opportunity to fully realize the numerous schedule and cost benefits inherent in modern I\&C technology.

I\&C systems of the domestic NPPs now in service primarily utilize hardwired analog and relay technologies from the 1970 s and 1980s. Even in situations where modern digital technology has been employed on an upgrade basis, it has been constrained within the asbuilt I\&C architecture which limits realization of digital technology benefits.

In the hardwired I\&C architecture, most plant sensors and components are wired directly (with intermediate terminations) to corresponding indication and control devices in the main control room. This parallel plant wiring approach to data communication provides the advantages of nearly instantaneous time response and immunity to multiple consequences from single failures. The equipment and labor costs, however, are very high. The complexity and magnitude of implementation is a contributor to the overall plant construction schedule which imposes an additional cost penalty.

Digital technology makes possible serial communication of multiplexed data. Data is concentrated closer to sensors and de-concentrated closer to actuated components resulting in far less field cabling between various parts of the plant. Computer based operator displays and controls eliminate most of the large amount of control room wiring required for discrete, spatially-dedicated controls and indicators. A design challenge is to realize the cost savings associated with these changes without degrading the performance, reliability, and availability of plant I\&C systems. It is considered prudent to retain a small amount of hardwire I\&C for 
highly critical functions such as manual plant protection system trips and actuation and monitoring of Reg. Guide 1.97 Category 1 variables.

In addition to reducing the amount of field cabling and panel wiring, digital data communication can employ fiber optic cabling. Not only is fiber optic cabling easier to install, it is impervious to electrical noise or faults. The result is that routing restrictions are minimized and safety channel separation is less costly to achieve.

In accordance with the principals outlined above, a CENP Nuplex 80+ Advanced Light Water Reactor design concluded that a 70\% reduction in cable related material and labor could be achieved based on the following reductions:

- $4,000,000$ linear feet of cable

- 54,000 linear feet of cable tray

- 85,000 terminations

- 35,000 linear feet of conduit

Advanced I\&C human engineered control and display features provide a basis for reduced operator staffing requirements. Human Supervisory Interface (HSI) features have been designed specifically to provide operators with the information and control capability required to perform their operational tasks, with reduced staffing as a goal. Operator burden is reduced through advanced alarm management and automatic channel checking, functional testing and data archiving. Automated sequencing can be used to reduce the number of individual steps an operator must perform to conduct routine and repetitive evolutions.

As a result of these, and other HSI design features, the advanced control room should make possible plant operation from hot standby to full power with one control room operator. Reduction in the number of equipment operators required for operations performed outside the control room is facilitated by the increased capability for centralized control. An advanced control room can also accommodate a wide variety of control room staffing levels, during both normal and emergency operations.

Vintage NPP I\&C process equipment uses a large quantity and variety of relays to accomplish logic and component control functions. They also use a large number and wide variety of analog electronic modules to accomplish process control functions (e.g., multipliers, square rooters, function generators, bistables, etc.). In advanced I\&C systems, all these hardware logic and control functions are accomplished in software allowing standardized digital system hardware components to be deployed in a wide variety of applications.

In conventional control rooms, more than one hundred unique components are required to implement operator interface functions in hard control panels. This is largely because of many meters, recorders, manual-auto stations, buttons, switches and dials are unique to their specific application. In an advanced control room, only 10-15 unique components are required due to standardization. 
As a result of the standardization described above, it is estimated that the combination of advanced I\&C and HSI results in at least a 50\% reduction in spare parts inventory for an NPP unit.

The recommended changes to design codes and standards address the unique attributes provided by digital technology. The low current and low potential employed eliminates the need to perform formal analyses on the use of cable splices, software reliability criterion can be based on minimum number of operating years for commercially available digital systems dedicated to safety applications, single safety system channel testing without channel bypass can be permitted based on demonstrated acceptable system reliability. In addition permit use of commercially accepted quality assurance programs to meet 10CFR50, Appendix B requirements and permit the use of periodic automatic on line testing during reactor operation. These types of modifications to design codes and standards will reduce the cost of safety system design, procurement, installation, and testing. 


\subsection{Task Y-1.7 Evaluate Excess Margin}

\subsubsection{Task Y-1.7 Approach}

In the current practice of evaluating seismic performance, individual sub-systems such as buildings, piping and equipment are modeled separately and interactions between them ignored by making conservative assumptions. Consequently, these sub-systems and components are highly over-designed leading to high construction as well as operating costs. Excessively conservative seismic loads resulting from the current practice leads to stringent qualification requirements for a large number of mechanical and electrical equipment. Excessively conservative requirements for seismic qualification make it practically impossible to use commercial grade items in a nuclear power plant. In addition, the qualification procedures such as vibration testing of equipment are time and cost intensive. Our work in this project can be categorized into two parts: (i) Elimination of excessive seismic margins in building-piping systems leading to hardware reduction such as snubbers. (ii) Development of simple web-based tools for reducing the seismic qualification and procurement costs associated with electrical and mechanical equipment. The work described below in this report was supported collectively by the resources from the following organizations: NERI grant from Department of Energy, member organizations of the Center for Nuclear Power Plant Structures, Equipment and Piping, and NC State University.

\subsubsection{Seismic Behavior of Electrical Cabinets and Control Panels}

Safety related electrical instruments are typically qualified by a shake table test. The earthquake input motion needed in such a test is defined in terms of incabinet response spectrum. In older plants, included in the unresolved safety issue A46, incabinet spectra are obtained by using simple amplification factors (often termed as SQUG factors) or other simplified procedures based on envelope techniques. It has been shown that in most cases these spectra are excessively conservative resulting in excessive seismic qualification requirements. In the non-A46 plants, the most commonly used incabinet spectrum is the standard spectrum recommended by ANSI/IEEE. This spectrum is used independent of the instrument location inside the cabinet, the type of cabinet of which the instrument is mounted, and the floor on which the cabinet is located. Consequently, they too are extremely conservative. Alternatives include vibration testing and finite element analysis of the electrical cabinet. Both these methods are time and cost intensive. They cannot be used repeatedly for generating incabinet spectra at different instrument and cabinet locations.

We are studying the seismic behavior of electrical control panels by performing detailed analyses. The analytical models are correlated with experimental data from laboratory as well as in-situ tests. Observations from the detailed studies are used to develop simple and easyto-use methods that can be implemented into spreadsheets or by web-based tools. Such a tool can be employed for evaluating realistic qualification requirements depending upon the location of instrument as well as the cabinet. Simplicity in the use of these methods will 
provide the flexibility for immediate reevaluation due to changes at various stages of design, construction, procurement, installation and operation. Time as well as cost associated with qualification and procurement can be significantly reduced by eliminating N-stamp requirements for certain instruments and by an online implementation.

\subsubsection{Building-Piping Systems}

NCSU participated in a benchmarking study conducted by Brookhaven National Laboratory, under contract to US Nuclear Regulatory Commission, for validating the methods for seismic analysis of non-classically damped building-piping systems. The outcome of this study has been published in NUREG report (NUREG/CR 6661, January 2000). The conclusions reached in this study are expected to facilitate the use of these methods in the design and operation of piping systems for future nuclear power plants.

In addition to conducting the validation studies, we illustrated application of coupled building-piping system analysis for evaluating excess margins and eliminating snubbers in an actual main steam piping, shown in Fig.4.7-1. The figure represents jacketed piping in which the process pipe has two segments of $32 \mathrm{inch}$ and 34 inch diameters that are connected through a reducer. The guard pipe has a diameter of 42 inch inside the reactor building and 40 inch inside the auxiliary building. There are a total of 13 snubbers in this part of the piping system. Two additional snubbers are located on a space truss used for supporting the isolation valve. In the original design of this piping system, all the supports and snubbers are modeled as rigid. The supporting structure for this piping consists of the reactor building, the reactor coolant loop and the auxiliary building. The results from an uncoupled analysis of the piping with floor response spectra as the earthquake input are compared to those evaluated from a coupled building-piping system analysis.

Figure 4.7-1

\section{Main Steam Piping with Snubbers}

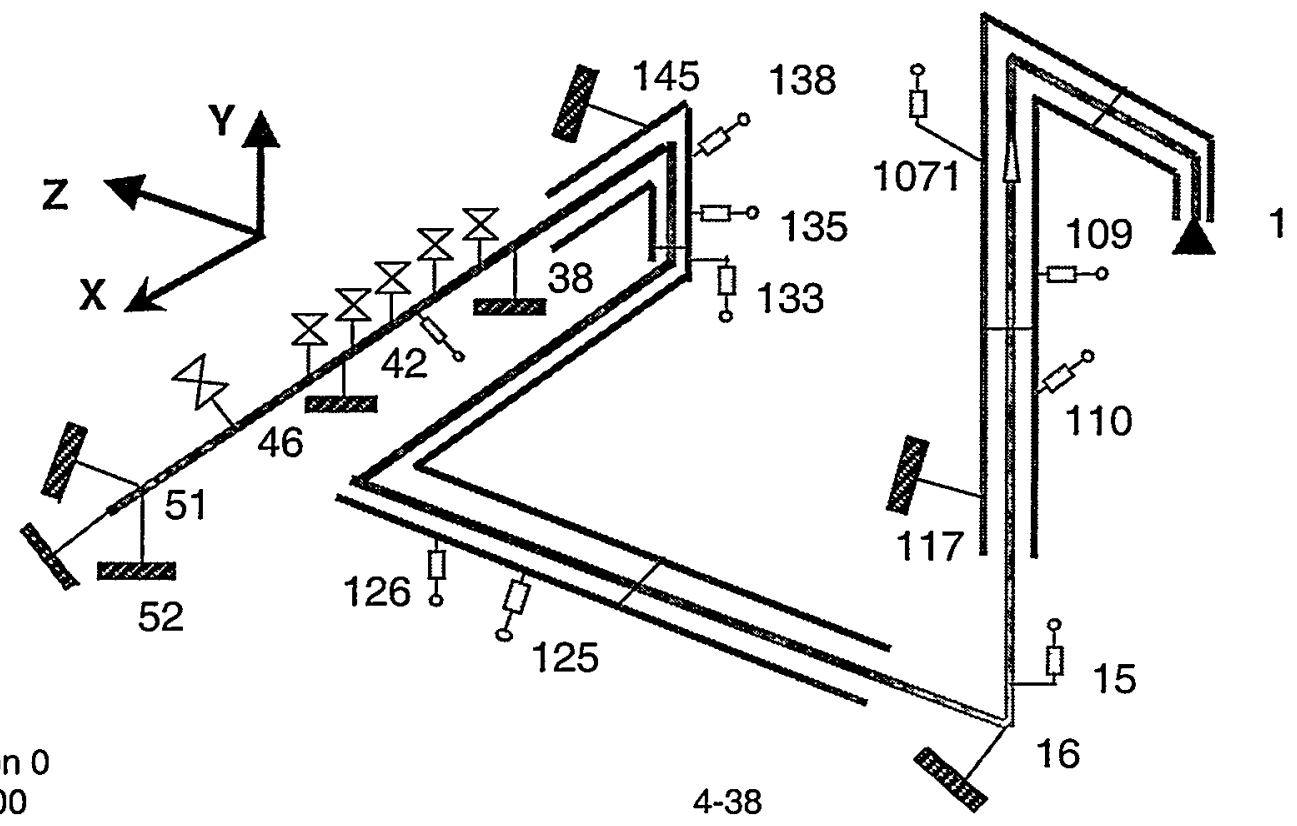




\subsubsection{Electrical Cabinets and Control Panels}

Figure 4.7-2 compares the actual incabinet spectrum in a particular cabinet with that developed using the current practice. This comparison shows the excessive conservatism in the current seismic qualification requirements for electrical instruments.

Figure 4.7-2

\section{Incabinet Spectra, Actual versus Current Practice}

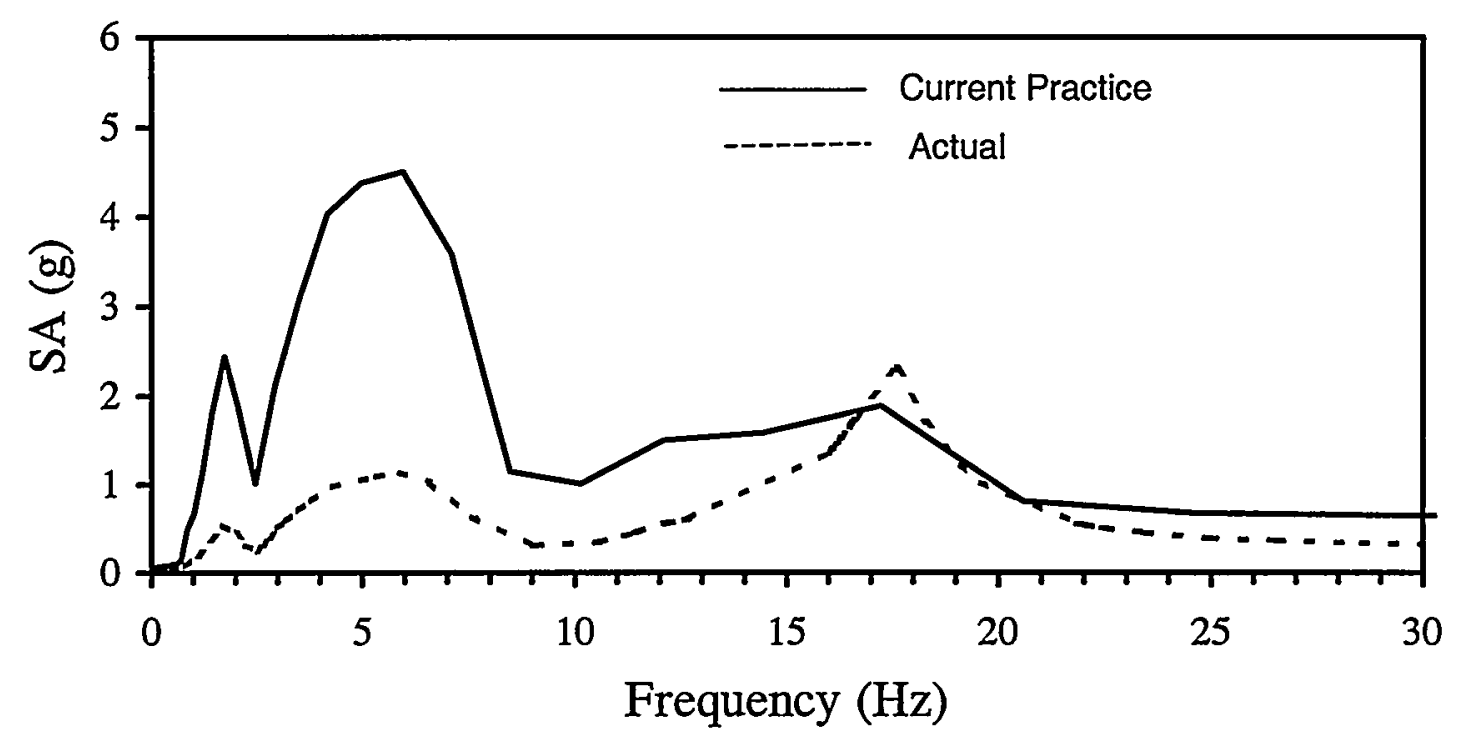

Detailed studies were conducted to study the dynamic behavior of cabinets. For a switch gear cabinet, the experimentally evaluated spectra were compared to those evaluated from rationally developed finite element models. The following conclusions were reached from detailed finite element analysis of several actual electrical control panels and reconciliation of analytical results against experimental data.

- Accurate incabinet response spectra can be evaluated using only a few (often only one) significant modes of vibration for the electrical cabinets and control panels.

- Significant mode is either a local panel mode or a global cabinet mode. It can also be a superposition of these two modes.

- Box type cabinets that have steel panels on all four sides and top can vibrate in rocking mode but not in global bending mode due to high in-plane stiffness of steel plates.

- Cabinets that are anchored to the floor are likely to vibrate in rocking mode. However, cabinets that are welded to the floor along its edges will not undergo rocking. 
- Dynamic characteristics for significant modes of vibration can be evaluated using simple mathematical functions and expressions 


\subsection{Task Y-1.8 Component and Quality Lead Time Constraints}

\subsubsection{Task Y-1.8 Approach}

As the DPCIT cycle time is reduced, the ability to deliver long lead equipment to support the reduced schedule will become more critical. The steam generators have been identified as the Nuclear Island equipment with the longest fabrication span. A study was performed to identify potential fabrication span reductions to ensure that a reduced DPCIT cycle can be supported. Additionally, the project team speculated that with fewer manufacturers willing to meet the various nuclear quality assurance requirements, there might be delivery time issues that could be addressed with revised quality assurance measures.

\subsubsection{Nuclear Quality Requirement Issues}

The requirements for $\mathrm{N}$ stamp vendors and other types of certifications may pose a challenge to the shortened schedule and cost targets for this project. The team conducted a review of the use of existing codes and standards embedded by reference to requirements found in 10CFR50.

Nuclear QA was born of the necessity to compensate for a lack of experience in assuring that the combination of components could be trusted to protect the health and safety of the public. While safety assurance methods for items such as pressure vessels (e.g. reactor vessels) are well known, there was insufficient confidence regarding the entirety of the systems designed for containment and to assure adequate core cooling. Subsequent operational history has occurred since the 1950's with both naval and commercial nuclear plants in the United States. Therefore, there is now a historical record upon which to base a revised quality assurance program.

Nuclear power plant components are required to meet many requirements. Performance requirements are specified by a system designer, based on the intended operation of the plant. Additional requirements related to the quality classification of the components are often dictated by regulatory authority and industry standards organizations. The US Nuclear Regulatory Commission refers to these additional requirements as Special Treatment items..

This effort reviewed the schedules and costs for procurement of components used in nuclear power plants. As expected, the schedules are longer and the costs are higher for components that are designated as safety related and therefore have special requirements for design, fabrication, testing and qualification. Conversely, commercial products that perform similar mechanical functions (pumping, heat transfer, and flow control or isolation) can generally be procured more quickly and cheaply. Table 4.8-1 summarizes the comparison of typical schedules and costs for commercial versus safety-related components. 
Table 4.8-1

\section{Summary of Procurement Schedules and Costs for Nuclear Power Plant Components}

\begin{tabular}{|c|c|c|c|}
\hline \multicolumn{3}{|c|}{ Procurement Schedule } & \multirow{2}{*}{\begin{tabular}{l}
\multicolumn{1}{c}{ Cost } \\
$\begin{array}{l}\text { Commercial Product as } \\
\text { a percentage of Safety } \\
\text { Related }\end{array}$
\end{tabular}} \\
\hline $\begin{array}{l}\text { Typical } \\
\text { Component }\end{array}$ & $\begin{array}{l}\text { Typical } \\
\text { Schedule } \\
\text { (Weeks) }\end{array}$ & $\begin{array}{l}\text { Reduction for } \\
\text { Commercial } \\
\text { Grade }\end{array}$ & \\
\hline $\begin{array}{l}\text { Centrifugal } \\
\text { Pump }\end{array}$ & $\begin{array}{l}70 \text { (safety) } \\
50 \text { (commercial) }\end{array}$ & 20 weeks $(30 \%)$ & $\begin{array}{l}25-30 \% \text { compared to } \\
\text { Code* pressure boundary } \\
\text { and } 1 E^{* *} \text { motor } \\
80 \% \text { for pressure } \\
\text { boundary only }\end{array}$ \\
\hline $\begin{array}{l}\text { Heat } \\
\text { Exchanger }\end{array}$ & $\begin{array}{l}90 \text { (safety) } \\
45 \text { (commercial) }\end{array}$ & 45 weeks $(50 \%)$ & $70 \%$ \\
\hline $\begin{array}{l}\text { Valve and } \\
\text { Actuator }\end{array}$ & $\begin{array}{l}\text { up to } 85 \text { (safety) } \\
\text { up to } 77 \\
\text { (commercial) }\end{array}$ & 8 weeks (10\%) & $44 \%$ \\
\hline
\end{tabular}

* Code = designed, fabricated, and tested in accordance with the ASME Boiler and Pressure Vessel Code, Section III, for Nuclear Power Plant Components.

** $1 E$ = designed, fabricated and tested in accordance with IEEE 308, Safety Criteria for Class 1E Power Systems.

Given that ISO 9000 and its derivative standards are becoming commonplace in the United States, replacement of certain aspects of the current QA requirements will be possible. Based upon the existing program descriptions embedded in law and regulations, this project did not find any short term gains to be made in this area. However, in developing comparisons of the System $80+$ design and the proposed AP1000 reactor designs (both from Westinghouse) it is clear that reducing the safety related building footprint is a key strategy. For instance in the System $80+$ design additional space was allocated within safety related areas for larger work areas and non-essential shop areas. In retrospect this use of high cost floor space constitutes unneeded costs and does not provide a benefit commensurate with the expense. Operations and maintenance for existing power plants has been shown to be accomplished within the constraints of the 1960's and 70's designs that were not optimized for maintainability. While the authors of this study do not suggest sacrificing maintainability per se for cost reduction, any non-safety used of safety related floor space or volume should be carefully considered. This is an example of how well intentioned efforts lead to incremental cost increases which prove difficult to back out in later analyses. 
One strategy is to reduce the footprint of safety related systems. This will reduce the total impact of the need for quality programs. Regulatory change programs that parallel the thrust of the risk informed regulations can be applied to the quality assurance area to realize improvements in this domain. Our conclusions on this matter are that changes to the quality assurance requirements represent significant programmatic change beyond the capability of this study to address due to their wide ranging nature. Future quality assurance programs may be able to take advantage of ISO 9000 based procedures to obtain safety related equipment not otherwise governed by codes such as ASME Section XI or the Boiler/Pressure Vessel Code.

\subsubsection{Steam Generator Fabrication}

Reductions in the overall DPCIT cycle must consider the fabrication spans for long lead equipment. The cycle must ensure that the equipment can, either be delivered in time to support the reduced cycle time, or the construction plan can be adjusted to allow equipment installation later in the schedule without increasing the overall DPCIT cycle. Historically, the steam generators are the critical item for fabrication in the Nuclear Island.

Even though steam generator fabrication spans have generally gotten shorter over the years, further improvements are needed to support reduced DPCIT cycles. The primary purpose of this study was to develop a 30 month fabrication schedule for two steam generators beginning with placement of material purchase orders and ending when both units are loaded for shipment at the Equipment Supplier facility.

The time span required for steam generator fabrication will vary depending on many factors. These factors include design details of the steam generators, plate or forged construction, fabrication facilities and the production equipment available, weeks per year/days per week/shifts per day worked, material lead times, assembly sequence, and experience level of the fabricator. In general, the trend has been for fabrication spans to be reduced but comparisons are not easily understood since one or more of the factors mentioned above will usually vary from contract to contract.

As a point of reference, a large System 80 economizer unit steam generator like Palo Verde could be built in the Chattanooga shop on a 52 month schedule. This was based on plate construction and working 48 weeks per year, 5 days per week and 3 shifts per day. Included were about 2 months of preliminary activity before the first material procurement order was issued.

Later, the Chattanooga shop quoted an even larger System $80+$ economizer unit steam generator for Taiwan in about 50 months based on forged construction and working critical path items for 50 weeks per year, 6 days per week and 3 shifts per day. Included were about 6 months of preliminary activity before the first material procurement order was issued. Palo Verde replacement steam generators are large units similar to the System $80+$ design and are currently being fabricated by Ansaldo on a 48 month schedule. This is based on forged construction and probably working 48 weeks per year, 6 days per week and 2 shifts per day. Included are about 3 months of preliminary activity before the first material procurement order is issued. 
For the Yongwang plant in Korea, a small version of the System 80 steam generator design was fabricated by Hanjung in about 46 months. This was based on forged construction and probably working 50 weeks per year, 6 days per week and 3 shifts per day. Included were about 2 months of preliminary activity before the first material procurement order was issued. This was the first System 80 design generator built by Hanjung and similar contracts were later built in about 40 months under the same conditions.

\subsubsection{Steam Generator Fabrication}

The steam generator fabrication schedule for $1000 \mathrm{MWe}$ System 80 plants can be reduced to 30 months. The results are based on Chattanooga shop experience and current technology. Some assumptions have been made that could impact the need for shop resources. Only an experienced fabrication vendor should attempt to meet this aggressive schedule. The 30 month period begins with the placement of material purchase orders and ends with the steam generators ready for shipment to the plant site. Similar schedule reductions can be achieved for larger steam generators. There are a number of critical assumptions that are required to be met to support parallel fabrication of steam generators. These have been described below.

\section{Parallel Path Fabrication Assumptions}

- One of the original assumptions for this study was that adequate $\mathrm{N}$-stamp shop facilities are always available so that work is not limited by resources. Now that an improved schedule has been developed, the impact on shop resources can be better defined as described below. Standard work times and shop performance efficiency needed to meet the improved schedule requires a skilled work force. An inexperienced vendor would not be acceptable.

- Both steam generators must be fabricated at the same time with no intervals between them. This means that both sets of material must be available at the same time and may require procurement from different suppliers.

- Tubesheet drilling is based on two 5-spindle drills that utilize BTA tooling.

- The shop must have duplicate sets of equipment necessary for other shop operations when fabricating two steam generators in parallel. Examples are welding, cladding, machining, $x$-ray, furnace, etc.

- Girth seam welding must utilize more than one wire in the process (e.g. tandem or three wire).

- Hydrostatic testing must utilize mechanical closures in lieu of welded caps.

- Wait times between major shop operations must be minimized. 


\subsubsection{Steam Generator Fabrication Shortening Strategies}

A significant schedule reduction span can be achieved for smaller steam generators using conventional tactics such as working more days per week and recognizing shorter spans for selected critical activities such as tubesheet drilling. For larger units like the System 80+ design, more unorthodox measures may be required.

In addition to development of a 30 month Primavera schedule for this study, a list of alternate ideas was also generated. The ideas were directed primarily towards improving the fabrication span for larger units, but most if not all of the ideas could also be applied to smaller units. Any of these ideas could be the subject of further evaluation if additional reductions are needed or desired. Each item has been ranked based on significance of impact on schedule and anticipated success in getting the change approved.

The symbols $\mathrm{H}$ (High), $\mathrm{M}$ (Medium), and L (Low) do not have absolute values associated with them but are relative to each other. As a point of reference, the $\mathrm{H}+\mathrm{items}$ could potentially result in several months of schedule reduction. Others are more likely to be in the range of weeks or days. Further study would be required to better quantify the schedule savings. Items with a combination of high schedule impact and high probability of success should probably be given first priority for study.

A brief description of each item in the table is provided below. In some cases, only cost versus benefits would have to be evaluated before implementing the ideas. In other cases, design changes would have to be generated and approved. For one item, a change to the ASME Code may be required. Studies could be done for each item to better quantify the true schedule impact and feasibility of implementation.

Item 1 - Stockpile long lead material $(\mathrm{H}+/ \mathrm{H})$

Certain critical path materials such as tubesheet and lower shell forgings could be stockpiled for one or more SG designs. The current material lead times are in the range of four to six months. However, other items might also have to be stockpiled to realize the full potential for saving schedule since they would become critical path.

\section{Item 2 - Stockpile subassemblies $(\mathrm{H}+/ \mathrm{M})$}

It may be beneficial to perform early fabrication steps for selected subassemblies and place them in stock. An example might be to clad tubesheets but more financial risk is involved than for simply stockpiling materials.

Item 3 - Improve tube installation $(\mathrm{H} / \mathrm{H})$

Currently, the System 80 generators have tubes, which are installed by rows (except for the initial rows of tubes essentially to the double ninety degrees bend tubes). This is slower than other designs which are able to install the tubes by line (a whole line of tubes during one insertion). A study should be conducted to look at methods and possible design changes to the upper tube support structure that permit more streamlined tube bundle assembly. 
Item 4-Improve method of tubesheet drilling $(\mathrm{H} / \mathrm{H})$

Currently, the tubesheets are drilled on one numerically controlled (tape or programmed) machine with one to three spindles active. A study should be conducted to explore alternate methods that can achieve the required positioning and drilling in a more efficient manner. The larger designs have over 25,000 holes in a 25 inch thick tubesheet.

\section{Item 5 - Redesign upper shroud and separator plate connection $(\mathrm{H} / \mathrm{H})$}

A $360^{\circ}$ weld is currently used to attach the separator support plate to the shroud. If a mechanical connection could be designed, assembly would probably be faster than making the weld.

\section{Item 6 - Use mechanical hydro plugs $(\mathrm{H} / \mathrm{H})$}

Some nozzles have historically used welded hydro caps that must be removed so the nozzle ends can be final machined. Any machining at that stage of fabrication is in the critical path.

\section{Item 7 - Use bolted couplings for internal piping $(\mathrm{H} / \mathrm{H})$}

This idea applies primarily to recirculation piping although it might be implemented for auxiliary feedwater piping as well. Because of access, internal piping must be welded after the pieces are inside the SG. Assembly time should be shorter if mechanical connections are used.

Item 8 - Simplify shroud supports to minimize welding $(\mathrm{H} / \mathrm{H})$

Shroud supports are currently welded to the pressure boundary shell. It may be possible to simplify this design so the amount of welding is reduced.

\section{Item 9 - Perform UT instead of X-ray on welds (ASME Change) (H/M)}

UT has already been recognized as a suitable equivalent to $\mathrm{X}$-ray by some ASME Code sections possibly even in Section III by errata. This method of inspecting welds is much faster and more easily incorporated, particularly for the SG closing girth welds, than using the X-ray technique if the ASME approval can be obtained or verified.

\section{Item 10 - Improve feedwater box design (H/M)}

It may be possible to reconfigure the feedwater box design to make installation simpler. Ideas at this time are rather vague but there was a consensus that some improvement might be made.

\section{Item 11 - Simplify snubber arrangement (H/M)}

A study could be made to look at improved designs for better fabrication methods and for improved means to align and install in the field. 
Item 12 - Design a modular tube bundle $(\mathrm{H} / \mathrm{M})$

This idea is complicated but could reduce the time required for tube installation. Many areas might be impacted by this design change and each would have to be evaluated before implementation.

Item 13 - Install dryers as a module $(\mathrm{M} / \mathrm{H})$

Dryers are currently installed after the top head is welded to the upper shell. It may be possible develop an arrangement for installation as part of the top head subassembly.

Item 14 - Install separators as a module $(\mathrm{M} / \mathrm{H})$

Separators are currently installed as individual units just before shipment. It may be possible to develop an arrangement where they are installed as part of the separator support plate assembly.

Item 15 - Eliminate pressure boundary weld seam PWHT by using nickel alloy butter $\underline{(\mathrm{M} / \mathrm{H})}$

At first glance, this idea seems simple and uses techniques proven for safe end and other welds. However, more steps are added to the welding process so the amount of schedule saving is debatable.

Item 16 - Simplify upper tube support design (M/M)

A study could be made to improve the upper tube support area. This study would focus on reducing the amount of welding and improving the critical path sequencing in order to provide a reduced span for the SG.

Item 17 - Simplify support skirt bolting arrangement (M/M)

Currently the support skirt bolt holes are used for alignment purposes as well as to anchor the steam generator in place. There may be more efficient methods of alignment that would allow more generous tolerances on the bolt hole pattern. Some method of attachment other than bolting should be explored.

Item 18 - Improve eggcrate design $(\mathrm{L} / \mathrm{H})$

The Sequoyah RSG will probably have some changes to the eggcrate design so that contact with tubes is minimized. Although not obvious, this could result in easier tube installation and translate into schedule savings. 


\subsection{Task Y-1.9 Develop System Dynamics Model for DPCIT}

\subsubsection{Task Y-1.9 Approach}

The purpose of this project is to try to model the DPCIT process and identify the major factors that contribute to the process cycle time in building such a model. First, a causal loop diagram is constructed to present a picture of how the various parts of the system interact. Next, a "stock and flow" diagram is constructed which defines quantities that are conserved in the project and demonstrates how they interact with other variables in the system. These "stocks" ultimately control how the model reacts to the influence of all the project variables. Once the diagram has been constructed and tested for errors, experts in the process are interviewed and data collected to ensure that the results are accurate. The major advantage of this type of model is its ability to show the nonlinear feedback effects of the variables in the process. It is thus an aid in finding the best way to manage problems that arise.

The causal loop has been constructed. The stock and flow diagram development is in progress. A stock and flow diagram has been constructed and tested for the design phase. A separate diagram has been finished construction phase, but has not been tested for errors.

Figure 4.9-1

\section{Example of Causal Loop}

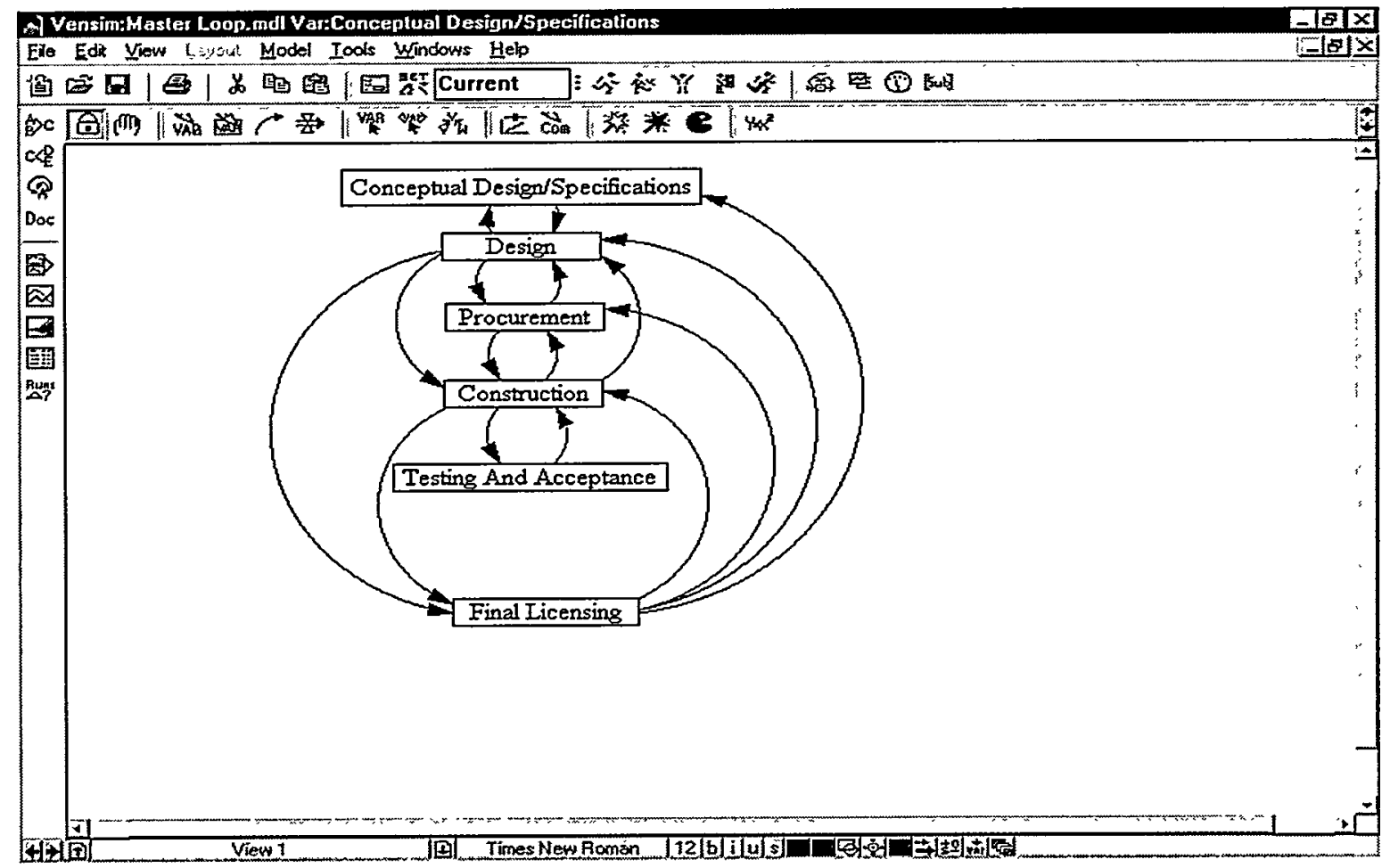


The entire model has been finished. Future work is to begin collecting data to adjust the magnitude of the variables and validate the accuracy of the results. This model should also be very useful as an element of a larger project which will use Bayesian Belief Networks to construct a distribution to describe the probability of finishing the construction of a nuclear power plant at or below a specific cost given the conditions of the construction process at the time of calculation.

\subsubsection{Process Modeling}

Engineers and scientists have developed very useful tools for modeling linear, physical processes. However, many of the most prominent problems facing engineers today have very important nonlinear components, including positive and negative feedback. Feedback has major effects on the dynamics of the system. Our next step as engineers is to develop tools that will address these problems. System Dynamics is a process that uses computer software to help analyze the dynamics of systems if the relationships between the different variables can be found. Thus, if variable $A$ affects variable $B$ which affects variable $C$ which in turn affects variable $A$, this process can be analyzed using System Dynamics.

The idea behind this particular project is to try to model the construction process of a nuclear power plant and to quantify the effects of changes that are implemented during the construction process. Historically, nuclear power plants have had extreme problems with cost and time overruns. Using Vensim DSS, a software developed for System Dynamics modeling, we intend to identify the components that play major parts in the construction process of a nuclear power plant and to quantify their effects. These variables can range from management quality to the morale of the various workers. Once these components have been identified and their interrelationships modeled, data from past experience must be inserted to test the validity of the model and to set the initial conditions. The model is then run under various conditions to test the effects of different actions and policies.

The process of modeling in Vensim is outlined below.

1. Draw causal loop diagrams which identify which components affect each other. This step DOES NOT identify the actual interaction.

2. Identify which variables are conserved, that is, their value can be changed only by moving part of the variable's quantity out or adding to it. This is called a level. Levels ultimately drive the model.

3. Identify the rates at which the quantities described by the levels flow from one level to the next or into and out of the model.

4. Finish connecting the variables to one another and formulate the equations describing the interactions.

5. Once the model has been completed and the equations verified, data must be input to 
the model from past experience. This data defines the initial conditions so that the model can simulate what happens in life.

6. The information gathered from the model must be analyzed to see if anything needs to be changed. This can include equations or even the entire model.

The major scope of our project is to identify the major causes and effects of change in the process of construction of a nuclear power plant. Currently, we have finished step 4 above and have enlisted the aid of an experienced engineer for data to use in the model. Once we receive this, we can see to what extent our model reproduces reality. Then, the process of reiterating the data input and equation formulation can begin.

\section{Figure 4.9-2}

\section{Vensim Diagram for DPCIT Modeling}

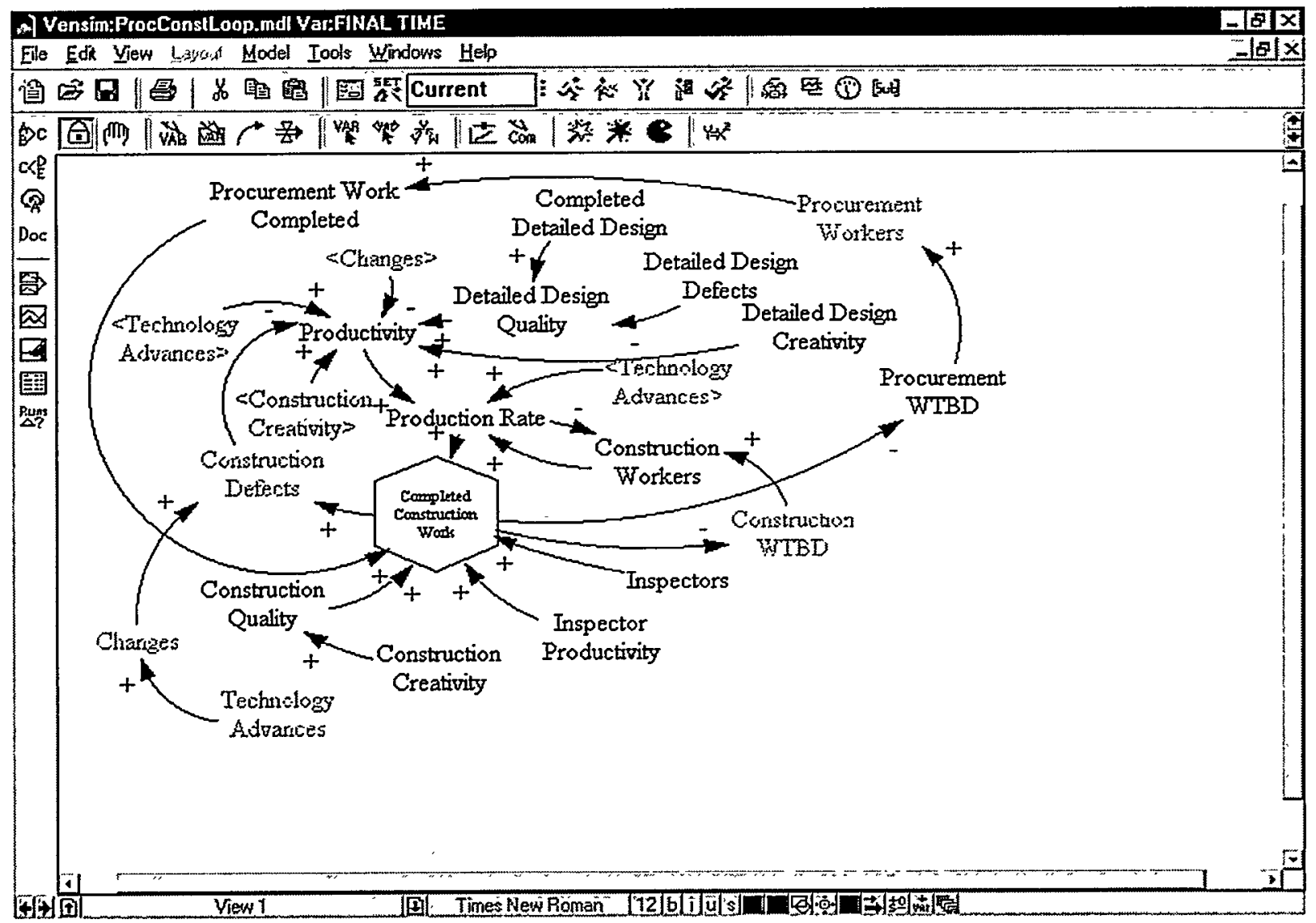




\subsection{Task Y-1.10 Linking Finite Element Codes and Design Software}

\subsubsection{Task Y-1.10 Approach}

Most analysts perform finite element analyses of structural systems and components by using a separate mesh generation program to develop numerical models based on the design drawings. While this procedure has been accepted as a standard practice, past experiences indicate that this procedure usually takes a considerable amount of time to implement, leading analysts to use much simplified numerical models to represent the structural configurations in order to reduce the model development costs. Consequently, most analysis results, which are usually not available during the design phase, can only provide confirmatory information on the design of structures and are not able to provide much needed information to improve the structural design. This problem becomes acute when the project team plans to manage changes initiated from design or operation needs and the analysis procedures cannot assess the effect of these changes on a timely basis.

In order to integrate the analysis effort with the project design functions, it is important to develop a computer software package on nuclear plant configuration that has the capabilities to perform the automated design-to-analysis process. The automated process allows analysts to generate finite element models, based on the same design data basis, to provide timely feedback to the design group in optimizing the plant/system design and streamlining the management of design changes. In summary, the automated process involves four steps: (1) Creating a solid model to represent/define the design geometry, (2) Translating the solid model representation to a format compatible with a selected finite element meshing tool, (3) Meshing the solid model to generate a finite element analysis model, and (4) Performing the analytical simulations of the finite element model with a numerical code.

The staff at Sandia National Laboratories is responsible for performing this task, with the support from Westinghouse Nuclear Systems and Duke Engineering and Services. The staff at the two industrial partners will select a component in a containment vessel as an example for demonstration and development purposes and provide the details of its structural configurations from an existing design. The automated design-to-analysis process will be exercised by first developing a solid model of the selected subsystem to implement all necessary joint connectivities and followed with the other subsequent steps.

In the past few years, Sandia National Laboratories has been involved in developing the automated design-to-analysis process to upgrade a weapons system under the Accelerated Strategic Computing Initiative (ASCI) program. Considerable success has been demonstrated and accomplished in this program. The expertise and technology base developed with this program will be leveraged and used in performing this task. 


\subsubsection{Target Component for Design to Analysis}

A pressurizer, a component in the reactor coolant system of the System $80+$ containment vessel, has been selected as the example for demonstration and development purposes in the automated design-to-analysis process. The selected structural subsystem includes the pressurizer assembly, its piping systems, and the surrounding building structures. In Year One, the process started with generating individual solid models of all parts of the pressurizer assembly using the Pro/ENGINEER (Pro/E) software package. A solid model of the pressurizer assembly was developed by linking all individual solid models of subcomponents with appropriate connectivity at the joint locations.

The next step in the process development involves a translator package that converts the contents of the solid model to a format compatible to a mesh generator. Different translator packages were investigated, depending on the nature of the analyses (such as seismic and thermal) and the element types (linear or nonlinear). Specific meshes of the finite element models of the pressurizer assembly were consequently generated using different software packages appropriate for the chosen analysis.

While Westinghouse Nuclear Systems handles the design details of the pressurizer assembly, the design data for the piping system and the surrounding building structures reside at Duke Engineering and Services. A well-coordinated effort is thus required to retrieve and gather all detailed information needed to develop the solid model of the pressurizer subsystem. Duke Engineering and Services plans to provide the design details of the piping system and the surrounding building structures in the early part of Year Two to allow the solid models of these subsystems to be generated.

A critical step in the development effort is to generate a solid model of the pressurizer subsystem that links the individual solid models of the pressurizer assembly, the piping system, and the surrounding building structures. Special attention will be focused on addressing the connectivity and interface between components at all joints locations. The mesh of the finite element model, generated from this solid model, will be analyzed through a selected solver code to demonstrate the robustness of the automated design-to-analysis process and to identify probable margins of design conservatism.

This task will also develop and maintain a product data management (PDM) system to enable designers, analysts and other project team members to share data from a common database, control access, track revisions, and data archival. 


\subsection{Task Y-1.11 Examine Containment Margins and Uncertainties}

\subsubsection{Task Y-1.11 Approach}

The containment system, which is a critical structural component in the nuclear power plant, takes up a significant portion of the total life costs to cover its construction and total life maintenance. It is therefore important to identify all uncertainties and risks associated with designing and operating the containment system in order to improve its cost management. Most of these uncertainties and risks are related to the postulated load conditions and scenarios against which the containment system is designed to uphold its system and structural integrity. Regulatory guidelines and procedures, which are deployed to manage these uncertainties and risks in its design, licensing, construction, and operation, are important in safeguarding the operation of the structure. This task focuses on examining the existing regulatory requirements on the containment system to identify the extent of the associated uncertainties and risks.

With the advancement in computer technology and the new development in finite element analysis codes and constitutive models, more sophisticated analyses, such as the coupled modeling of structural systems including components, piping system, and building structures, can be performed to assess the performance of containment systems under different loading configurations. The results from these coupled analyses provide more insightful information to address the range of the uncertainties on the design and the operational parameters of the containment systems. The related regulatory requirements may thus be revised to provide a more effective guideline to safeguard the operation of the containment system.

The task effort focuses on (1) examining containment design criteria and safety margins based on existing regulatory guidelines, and (2) identifying and assessing uncertainties in containment design, analysis and operations. The first task will be performed in Year One, followed by the second task in Year Two. The merits of revising the regulatory guidelines and their fundamental assumptions will be evaluated in Year Three to improve the procedures to manage the associated uncertainties and risks.

\subsubsection{Containment Margin Examination Results}

There was a series of five Workshops on Containment Integrity, sponsored by the U.S. Nuclear Regulatory Commission, in 1982 - 1992. The purpose of these workshops was to provide an international forum for the exchange of information on the performance of containment systems. The proceedings issued from each workshop provide a resourceful data basis for examining the containment design margins and uncertainties.

In Year One, a literature survey on the workshop proceedings was completed to identify and examine various parameters that have direct impact on the design and cost management of containment systems. These parameters include construction management and quality assurance, material selection, loading and design, and analysis methods. The survey process 
focused on collecting information on the existing containment design principles and maintenance practices to safeguard against structural failure.

In Year Two, each identified parameter of the containment systems will be evaluated by compiling its ranges of variation from existing data basis and performing Monte Carlo analyses to provide risk-informed performance assessments. In Year Three, the existing design and operation procedures of containment systems will be examined to reduce the total life costs by improving the management of associated uncertainties and risks. 
5 MOdeL DeVE LOPMENT 


\subsection{Product Model}

The Product Model is represented by the three-dimensional engineering design model, described in Section 4.3. This model describes the structures and equipment in the plant and their physical relationships. Many of the delays and cause of rework for both design and construction are the result of the interfaces between the structures and equipment. Electronic aided design is becoming common place for component and equipment design, as well as plant layout and structure design. The ability to integrate equipment and component models into the plant model is an area that requires improvement to achieve the maximum benefit of electronic aided design.

Using the component and equipment models developed by the equipment designers in the Product Model is preferred over having to redoing the models in the plant model software. Interface data can be more completely defined the equipment designers. Time and potential errors can be reduced by eliminating the need to redraw the models. Since the amount of component and equipment detail information needed is less than the amount required in the plant model, the ability to reduce the model sizes will reduce the time required to transmit information to the plant model, distribute the plant model and generate the images of the plant model. Equipment model reduction is discussed in Section 4.3.

Plant CMS software, described in Section 4.3, has been used to incorporate models with different formats for a number of projects. Additional research is required to automate the model conversion and distribution of the plant model to remote locations.

The document data base associated with the plant model can serve as the directory for and link to the design and construction documentation. The data base also could serve as the means for sharing other engineering models, such as, structural models of component, equipment and structures among the project participants. Using the document data base in the plant model, links can be developed to project management, supply management and construction management data that is required for the execution of the project. By associating inspection and installation data recorded during construction with the product model data base, the data will be stored in a manner that it is readily available during plant operation and maintenance.

With all of the plant information readily available through the Product Model, a construction supervisor can assemble all the information (drawings, procedures), verify material availability, plan and schedule material movement, identify and location special equipment required, and record the completion status (including quality assurance) of each work package that is assigned to him. 


\subsection{Productivity Model}

The Productivity Model is represented by the 4D model that is discussed in Section 4.1. Thus, the Productivity Model incorporates both the 3D design information and the sequence of the construction schedule. The construction schedule typically considered as the plan for conducting the plant construction and startup. In many cases for previous plants, the plant design is well underway before detailed construction scheduling occurs.

It is generally agreed that there are benefits to be gained from early development of the construction schedule during the preliminary design of the plant. The design can be checked for constructability considerations. Changes that could simplify the construction activities to decrease both the cost and duration of the construction period can be factored into the design if they are discovered early in the process.

\subsection{Process Model and the Management of Complex Projects}

The process model is intended to be a method of capturing and implementing best practices found in other industries as well as adapting new tools and practices to meet the needs for an improved schedule at a reduced cost and with a modest risk. The following sections cover the current thinking on what ought to be contained in the process model. The model will evolve over time as new practices are identified and validated.

The risk of undertaking large capital projects is another barrier to new advanced nuclear plant construction. While companies like Intel are undertaking one to two billion dollar semiconductor wafer plants on a fast track schedule with expected completion times within two years, the nuclear industry's ability to meet a much faster schedule remains to be proven. For companies like Intel, speed to market is a key factor in their success, thus the rework and field changes that are characteristic of fast track projects are tolerated within the overall cost of the project since time is the key variable. Our confidence in building new nuclear units will need to be improved to support new plant orders in the United States. Thus, the philosophy of the new nuclear power construction will be one of a fairly high assurance that cost and schedule can be met. To this end, and because of the licensing process needs, a complete plant design down to very fine levels of detail for safety systems will be required. These prerequisites will help ensure that the project plan can be undertaken. However no plan is immune from change and experience has shown that change will occur anway. Therefore our confidence in building from a complete set of plans and a predicted schedule will need to be reinforced with new project management methods. In the sections that follow, a few applications of existing technology to the project management domain are described.

\subsubsection{Process Model Element - Dependency Structure Matrix}

DSM is a methodology for describing and analyzing the information dependencies in webstructured problems for the purpose of planning its design or studying its behavior. The 
problem to be solved can be as diverse as a process (e.g., design or construction activity), a system (e.g., components, equipment or systems), an organization, or a system of equations. It is a way of showing what information depends on what other information in a problem so that one can see where assumptions are used and when the information necessary to review them becomes available. If and when an assumption proves to be incorrect, the DSM shows what needs to be redone and facilitates making a new plan or strategy for solving the problem.

DSM is a compact, matrix representation of a process, system, or more generally, a problem. The matrix contains a list of all constituent activities or elements of the problem and the corresponding information exchange patterns or relationships among them. Analyzing the DSM matrix allows formulation of plans to solve the problem (e.g., design a system or product). This plan will show the order in which the parts of the problem should be considered, where estimates must be used for information not yet available, how to iterate the analysis or design of subsystems, where design reviews are required and what must be reviewed, and how the design process should be managed. Such a plan can also show how the resources are scheduled and controlled, what is affected by changes, and how changes are controlled, documented and verified.

To study the DSM methodology further, an investigation was conducted to determine what tools were available to implement DSM and then to apply the tool to a straightforward problem that would illustrate DSM's applicability and potential.

A program called PSM (Problem Solving Matrix) produced by Problematics, Inc., was found from surveying available literature on the Internet and acquired.

The sample problem chosen was a process for the design of a steam generator using a past proposal network as a definition of the design activities. Activities from a Primavera network were taken directly and input into the PSM software to create a precedence matrix. Since PSM does not read Primavera output, the data input was performed manually. Over 335 activities were input, each has from one to as many as twenty dependencies. The matrix was then partitioned and the results examined.

The matrix representing the Primavera model initially showed many circuits-backward information transfers or coupling among activities-as indicated by the marks above the diagonal.

These results suggest that the activities characterizing the SG design process (at least as defined in the Primavera database) can be ordered so as to prevent circuits in the information flow characterizing the SG design process, and the banding of activities indicates concurrent engineering opportunities that can reduce critical path times.

It is the conclusion of this study that DSM has many viable applications. Applications involving design problems, particularly those characterized by a web-structure and having activity dependencies with circuits are most suited to DSM. DSM is a methodology that facilitates problem solving by organizing the structure of a problem so that strategies for its solutions can be developed that minimize cost, time and resource allocation. 
DSM uses matrices to represent the structure of a problem. This allows for rigorous analytical analysis that reduces analysis time and minimizes subjectivity. DSM's most powerful feature is its ability to explicitly and analytically treat circuit dependencies so as to organize the activities comprising the circuits into sequences which minimizes the number of assumptions that need to be made or the time needed to execute the solution of the problem (e.g., implementation of a design process) or the resources necessary to solve the problem. DSM can be used to coordinate the work of engineers collaborating on a design by helping in the formation of concurrent engineering teams, scheduling their tasks, seeking that they are provided with the right information when they need it, and transmitting the information they produce to those who need it.

DSM is an effective and convenient tool for analyzing relatively small-scale problems-problems defined by one hundred elements or less. Problems exceeding about one hundred elements are handled adequately by PSM (in fact, the example problem in this study had 337 elements), however, visualization of the partitioned matrix becomes cumbersome. The structural patterns the DSM methodology exhibits after partitioning and tearing are not conveniently observed in very large matrices. However, larger problems may be partitioned into smaller sub-problems and these can be effectively analyzed using PSM.

\subsubsection{Process Model Element - Bayesian Belief Networks}

Bayesian Belief Networks (BBNs) will be incorporated into the Process Model as the work progresses in Year Two. The value of BBNs is in their representation of conditional probabilities, that is if event $A$ occurs and there is a relationship to event $B$, then we can know what the probability of $B$ is given that we already know that $A$ has occurred. Our application for this type of technology will be to develop project management models capable of updating themselves once the project commences and we have captured the productivity data and can make comparisons to the project's assumptions. In this way, we would expect to update our project schedule and cost estimates and thereby have a better understanding of the outcomes being achieved. More importantly, this type of model updating gives us a chance to intervene earlier and more effectively than waiting for a large set of cost of schedule data to accumulate. It can be said that no project plan survives first contact with the real world situation once the project starts. Therefore, we wish to have a plan that can be updated and modified using our performance information with the goal of being better able to meet the cost and schedule requirements. 
6 EXPECTED RE SULTS NEXT YEAR 


\subsection{Model Development}

Year Two work will continue with enhancements to the models that have been developed in Year One. Due to the usefulness of considering the impact of the Westinghouse AP600/AP1000 design as a probable Generation IV reactor plant, the models will be modified to reflect the insights gained from inspecting the System $80+$ design (Generation III) versus the new design philosophies found in Generation IV. These contrasts will illustrate how design philosophies influence the cost and constructability of nuclear power plants.

\subsubsection{Productivity Model}

The Productivity Model, represented by the construction schedule, is one of the tools used to measure the benefits of changes to the DPCIT cycle. Changes developed in the DPCIT program, that impact the construction schedule, will be evaluated in terms of improvement to the baseline schedule developed in Year One of the program.

The availability of equipment for installation is an important element of the DPCIT cycle. Procurement of equipment becomes more critical as the overall cycle is decreased. Time spans for developing procurement requirements, equipment fabrication spans and delivery durations will be incorporated in the construction schedule. This information will assist in forecasting the expenditure profile of the construction program. Equipment that could impact the installation sequence will be identified in order to ensure the overall construction schedule considers the availability of equipment. Requirements for on-site warehousing can be more fully developed by the consideration of the equipment delivery dates.

The baseline construction schedule will be revised to reflect a higher degree of modularization of construction. Examples of areas that have been identified to date include:

- Shop assembly of reactor internals

- Concurrent reactor internals installation and reactor coolant system main loop welding

- Installation of reinforcing bar in the steel containment vessel dish prior to dish installation. 
The baseline schedule has identified the reactor building interior concrete placement as a critical item. Alternate strategies to reduce activity durations related with concrete placement will be investigated for their impact on the overall schedule. Potential areas of improvement include:

- Larger pool and tank modules and their use as left in place concrete forms

- Methods to decrease construction spans for the steam generator walls and polar crane wall.

- Modularized ICI guide tube chase.

Additional schedule improvements that are developed during the performance of other DPCIT tasks will also be incorporated in the construction schedule.

Enhancements to the Four-Dimensional Visualization software will be used to identify further potential schedule improvements. Enhancements include:

- Construction Quantities

- Update from PM-VISION to Primavera

- Schedule Integration with Intelligent Schematic Representation of the Plant

Construction Quantities relate to the bulk materials that are installed during construction. The physical parameters of construction objects in the three-dimensional construction model of the plant are currently related to activities in the construction schedule through the fourdimensional visualization. The physical parameters include volumes, surface areas and lengths. Through the association of a model object with a list of the material contained in the object, detailed installation rates for the bulk materials can be determined and displayed in the four-dimensional visualization. As an example, reactor building concrete has different amounts of reinforcing bar, forming requirements and concrete type. The visualization can be used to determine the amount and timing of the installation of these items that make up the object represented in the model. By combining the rates and timing for each construction activity, the project rates can be verified for practicality and to better forecast the project expenditure profile. This will increase the level of confidence in the ability to construct the plant on the proposed schedule and cost.

The ability to modify the construction schedule while using PM-Vision, the four-dimensional visualization tool, the ease of performing evaluations of alternate construction sequences will be enhanced. It is anticipated that this will allow evaluation of more alternative techniques, further increasing the confidence in the schedule and plant cost.

Integrating the engineering schematics, such as P\&D's and wiring diagrams, with the construction schedule and three-dimensional model will improve the ability to schedule system based activities in the construction schedule. 


\subsubsection{Product Model}

Further efforts on the Product Model, represented by the three-dimensional engineering model, are centered on the developing the methods to provide correct and complete interface information for the plant equipment to the project participants.

The ability to reduce detailed equipment design models, while maintaining all necessary physical interfaces, will be continued to be developed. For a large project, a method of incorporating diverse model formats into the plant three-dimensional engineering model is critical to eliminating engineering and construction rework that adds to the schedule and cost.

The ability to easily incorporate new or revised equipment models into the plant model in a timely manner is necessary to provide the interface information to all participants. Consideration needs to be given to automatic updates to the three-dimensional plant model and the subsequent distribution of the model to the participants.

The three-dimensional model is potentially the "roadmap" to all plant documentation and the link to project management and supply management tools. This could be accomplished through related databases.

The continuing work on the Product Model will focus on evaluation of interface control and project data management. Guidelines will be developed for execution of these items on a full-scale project.

The modularity project should be at a point where we can turn over a general layout of the design to interested parties for use in the design of a specific project by the end of September, 2000. This design will include sizes and shapes of a set of modules to use for constructing a nuclear power plant and the recommended method for assembling the modules. We will also decide on whether to use a hybrid approach or a totally modular approach. We will also include an explanation for our decision.

Extension of the work on qualification of electrical equipment to mechanical equipment and develop a web-based tool for implementing it.

The work on building-piping system will be extended to other components and sub-systems. Often, engineers and researchers have expressed the need of developing a large finite element model of all the structures and components in a power plant. Such a model will not only facilitate the visualization of interaction between components and sub-systems but also assist in studying the propagation of uncertainties from one component and sub-system to another interacting sub-system. However, creation of such a large finite element model is not only impractical but also impossible to analyze due to unavoidable numerical difficulties. Further, a particular component or sub-system interacts with only a few other components and subsystems. Consequently, the resources spent on creating and analyzing a large model that consists of every component or sub-system together with accounting for uncertainties in such a model would far exceed the corresponding benefits. Methods described earlier for buildingpiping system can also be extended for modeling of other interacting sub-systems and components at varying levels of refinement and yet synthesize them together to evaluate the behavior of a system that consists of interacting sub-systems. Such a synthesis will also avoid 
the numerical difficulties that are otherwise unavoidable. In addition, it will provide flexibility to generate alternatives of a particular component or sub-system with minimizing the remodeling of other interacting components or sub-systems. Formal approaches will be developed for model synthesis, evaluation of meaningful alternatives, and incorporating what-if approaches in design and decision making. It is also proposed to develop methods for incorporating the sensitivity of calculated seismic responses to the uncertainty in parameters.

\subsubsection{Process Model}

We expect to complete our work in modeling feedback in the DPCIT projects by December 2000. This work is described elsewhere in this report, using the System Dynamics technique. We expect the model to be valuable in quantifying the magnitudes of the consequences of changes in the project scope. Such consequences are typically underestimated in the absence of models such as ours, and we expect an optimized DPCIT project to be especially sensitive to the disruptive effects of unexpected changes. The use of our model is to resist such changes.

We also plan to begin work on a project that will include the results of the System Dynamics model in conjunction with software that utilizes Bayesian statistics to predict the outcome of different actions that can be taken. This model will show the user the different routes that can be taken to finish a project and the probabilities associated with each. We expect to have a usable model by the summer of 2001. In the Bayesian Project Monitoring Model, we shall utilize a Bayesian Belief Network, driven by project status data, to provide real-time estimates of the probability distribution of alternative project outcome states. This distribution will be conditional upon the values of the project status metrics and will utilize the project monitoring expertise of seasoned DPCIT project managers for interpreting the implications of the various metrics. The project staff is experienced in the use of Bayesian Belief Networks, (BBN). This work will employ the tested, commercially available BBN shell, Hugin.

\subsection{Containment and Structural Construction Simplifications}

Based upon the possibilities identified during the Year One work coupled with observations of critical path schedules for both System 80+ and the AP 1000 plant designs, work will be done to examine what simplifications in both design space and construction space can be made to reduce cost and schedule. Clearly, changes in regulatory underpinnings such as a vastly reduced pipe break size made possible by the adoption of Risk Informed Regulation would influence reductions in containment strength requirements. These changes could translate into simpler to build containments with less reinforcing material, thus permitting faster erection. The use of off site pre-built rebar modules coupled with faster concrete pour times could enhance the quality of construction due to minimizing the risk of voids in the concrete.

Simplification of construction methods will go hand in hand with 


\subsection{Project Risk Management Technologies}

The work described in the Process Model section illustrates our concern for the control of complex projects such that confidence can be generated not only in the proposed schedule and cost, but in the execution of the project once the project starts. Tools such as the System Dynamics modeling and Bayesian Belief Networks will be evaluated for their potential roles as advanced project management systems.

\subsection{Information Technologies}

The impact of information technologies continues to be keenly felt throughout the United States. There are continuing developments in new offers made possible with information technology. Our purpose in continuing to examine this area is to evaluate the use of various information technology strategies to the ability to design, procure, fabricate and construct much more swiftly. Collaboration is the hallmark of reduced cycle time in the automotive sector and information technology provides the mechanics of how that collaboration can be managed.

The construction of complex objects in a highly regulated environment can also benefit from our work. Management of the quality of the information produced throughout the DPCIT cycle is critical to ensuring that the facility meets the 10CFR50 license requirements without doubt. Past experience has shown that uncertainty about the quality of information concerning safety related systems or components undermines the regulator's confidence in granting new operating licenses. Therefore, information technology developments will play an increased role in ensuring that an advanced nuclear plant will demonstrate conformance to the regulations while at the same time being built in much less time and for less investment than prior nuclear construction. 


\section{APPENDIX A: PROJECT PARTICIPANTS}

Duke Engineering \& Services

O'Connell, J. Michael

$\mathrm{Pu}$, Cong

Bernier, Raymond

Gerardi, Michael

McRainey, Daniel

Oswald, Todd

Abernethy, Randy

Fischer, Daniel

Principal Investigator

Engineer

Project Manager

Engineer

Manager

Manager

Manager

Project Manager

Massachusetts Institute of Technology

Golay, Michael

Middleton, Bobby

Kwak, Sangman

Professor

Graduate Research Assistant

Ph.D.

North Carolina State University

Gupta, Abhinav

Gupta, A. K.

Assistant Professor

Professor \& Director of Center for

Nuclear Power Plant Structures,

Choi, B.

Equipment \& Piping

Yang, J.

Graduate Student

Graduate Student

Tan, $Y$.

Graduate Student

Lu, $\mathrm{X}$.

Graduate Student

Sandia National Laboratories

Luk, Vincent

Principal Member of Technical Staff

Rochau, Gary

Principal Member of Technical Staff

Westinghouse Electric Company-Nuclear Systems

Aldous, Teresa Ann

Assard, Maria E.

Austin, Steven A.

Berntsen, George P.

Bryan, Robert E.

Colin, Dreyfuss

Davis Jr., George A.

Gerdes, Lyle D.

Kielb, John F.

Luedke, Michael T.

Matteson, Donn M.
Scheduling Coordinator

Senior Engineer

Consulting Engineer

Senior Consulting Engineer

Senior Consulting Engineer

Engineer

Director Government Programs

Senior Consulting Engineer

Principal Nuclear Engineer

Consulting Engineer

Senior Consulting Engineer 
Westinghouse Electric Company -Nuclear Systems (Cont.)

Mullooly, John F.

Turk, Richard S.

Volodzko, Michael

Von Kutzleben, Bernd E.
Manager-Mechanical Design

Engineering

Engineering Manager-Systems

Development

Consulting Engineer

Senior Consulting Engineer 


\section{APPENDIX B: LIST OF PUBLICATIONS AND REPORTS}

O'Connell, J. M., Turk, R., and Matteson, D. "Report On NERI Research Project To Reduce Capital Costs And Plant Construction Time For Future Nuclear Power Plants:, Paper presented at ICONE-8 by J. Michael O'Connell, Duke Engineering \& Services, ICONE-8 Paper Number 8273, April 2-6, 2000.

Gupta, A.K., Gupta, A., and Bose, M.K., "Evaluation Of Methods For Analysis Of Nonclassically Damped Coupled Systems: Benchmark Program," Attachment 2 in Benchmark program for the evaluation of methods to analyze nonclassically damped coupled systems, NUREG report - NUREG/ CR-6661, eds. J. Xu and G. DeGrassi, Office of Nuclear Regulatory Research, US Nuclear Regulatory Commission, January 2000.

Yang, J., and Gupta, A., "Ritz Vector Approach for Dynamic Behavior of Electrical Control Panels," Proceedings of 14th Engineering Mechanics Division Conference, American Society of Civil Engineers, University of Texas, Austin, May 21-23, 2000.

Gupta, A., and Yang, J., "Stiffness of Mounting Arrangement in Switchgear Cabinets," to be submitted to 16th International Conference on Structural Mechanics in Reactor Technology, Washington, D.C., August 2001.

Clamp, Alice, "Making Tomorrow's Nuclear Plants Competitive, DOE Supported Research Team Seeks to Reduce Cost", Nuclear Energy Institute Insight, June 2000.

Stellafox, David, "Information Technology Seen Key To Cutting New Nuclear Plant Costs", Inside Nucleonics Week, Vol. 41 No. 16 April 20, 2000 


\section{APPENDIX C: KEY PRESENTATIONS \& MEETINGS}

DPCIT project was discussed at "Joint Meeting of the Steering Committee and Board of Advisors of the Center for Nuclear Power Plant Structures, Equipment, \& Piping," November, 1999.

Presentation at the $8^{\text {th }}$ Annual International Conference on Nuclear Engineering on Report on NERI Research Project To Reduce Capital Costs And Plant Construction Time For Future Nuclear Power Plants, April 3, 2000, Baltimore, MD, ICONE-8 Paper 8273 


\section{APPENDIX D: BIBILOGRAPHY}

Sugita, Hiroyuki, Advanced Construction Technologies for Future Nuclear Power Plants Volume 1, March 1996, Electric Power Research Institute, Palo Alto, CA

Schimmels, John N., Advanced Construction Technologies for Future Nuclear Power Plants

Volume 2, January 1997, Electric Power Research Institute, Palo Alto, CA

Lynch, Richard L. and Cross, Kelvin F., Measure Up!: How to Measure Corporate Performance. $2^{\text {nd }}$ Edition, 1995, Blackwell Publishers Inc., Cambridge, MA

Management of the Licensed Bases of Advanced Nuclear Plants: Proof of Approach. EPRI, Palo Alto, CA and Duke Engineering \& Services, August 2000. TR-1000056. 